This is a post-peer-review, pre-copyedit version of an article published in Corrosion Science. The final authenticated version of the paper " C. Chiavari, E. Bernardi, A. Balbo, C. Monticelli, S. Raffo, M.C. Bignozzi, C. Martini, Atmospheric corrosion of fire-gilded bronze: corrosion and corrosion protection during accelerated ageing tests, Corrosion Science, 100 (2015) 435-447”, is available online at: https://doi.org/10.1016/j.corsci.2015.08.013.

\title{
Atmospheric corrosion of fire-gilded bronze: corrosion and corrosion protection during accelerated ageing tests
}

${ }^{1}$ C.Chiavari, ${ }^{2}$ E.Bernardi, ${ }^{3}$ A.Balbo, ${ }^{3}$ C. Monticelli, ${ }^{2}$ S.Raffo, ${ }^{4}$ M.C. Bignozzi, ${ }^{5 *}$ C.Martini

${ }^{1}$ C.I.R.I. (Centro Interdipartimentale di Ricerca Industriale) Meccanica Avanzata e Materiali, Università di Bologna, Via Risorgimento 2, 40136 Bologna (Italy)

${ }^{2}$ Dipartimento di Chimica Industriale "Toso Montanari”, Università di Bologna, Via Risorgimento 4, 40136 Bologna (Italy); elena.bernardi@unibo.it

${ }^{3}$ Centro di Studi sulla Corrosione e Metallurgia “A. Daccò”, University of Ferrara, Via Saragat 1, 44122 Ferrara (Italy); cecilia.monticelli@unife.it

${ }^{4}$ Dipartimento di Ingegneria Civile, Chimica, Ambientale e dei Materiali, Università di Bologna, Via Terracini 28, 40131 Bologna (Italy)

${ }^{5}$ Dipartimento di Ingegneria Industriale, Università di Bologna, Via Risorgimento 4, 40136 Bologna (Italy); carla.martini@unibo.it

\section{Keywords}

A. Copper; A. Organic coatings; B. SEM; B. Raman spectroscopy; B. Polarization; C. Atmospheric corrosion

\begin{abstract}
Fire-gilded bronze (replicating the materials of Lorenzo Ghiberti's Paradise Door (Baptistery of Florence, 1452)) was aged in runoff/stagnant conditions by accelerated exposure tests in synthetic acid rain. After preliminary electrochemical investigations, a detailed characterization of gilded bronze samples before and after artificial ageing tests followed. Surface and cross-sections analyses were performed by FIB/FEG-SEM, SEM/EDS and micro-Raman spectroscopy. The protective efficiency of a coating based on 3-mercapto-propyl-trimethoxy-silane was also quantitatively assessed by GF-AAS through analysis of metal release, while the aesthetical appearance of coated and uncoated gilded bronze before and after ageing was evaluated by colour measurements.
\end{abstract}

\footnotetext{
*Corresponding author:

Prof. Carla Martini

Dept. of Industrial Engineering, University of Bologna

viale Risorgimento, 4

40136 Bologna, Italy

email: carla.martini@unibo.it

Ph. +390512093464
} 


\section{Introduction}

Gilded bronzes, widely used in historical monuments as well as in architectural elements, are often severely affected by corrosion damages, due to the presence of pores and defects in the gilded layer, that induces corrosion of the bronze substrate.

Defects and discontinuities in the gold layer are primarily due to the technological processes of gilding. The decoration of objects with surface gilding started by simply using gold foil (thickness > $1 \mu \mathrm{m}$ ), that could be applied mechanically (e.g by folding and crimping) on metallic substrates. Then, it evolved to the application of gold leaf (thickness $<1 \mu \mathrm{m}$, obtained by beating the metal in a parchment sheath), which required the use of an adhesive material paste [1]. A famous example of historical leaf-gilded bronze is the statuary group from Cartoceto di Pergola (Italy), which is the only surviving Roman gilded bronze equestrian group. In the case of leaf-gilded surfaces, discontinuities may arise from the junctions among foils/leafs, from scratches and mechanical damages in the gold foil/leaf and from areas where the adhesion of gold is not satisfactory. Particularly, in the case of leaf gilding, also bio-deterioration of organic adhesives might negatively affect the durability of the gold layer [2].

The ancient goldsmiths found an elegant solution to the problem of gold leaf elaboration and application by inventing amalgam- or fire-gilding, based on the use of mercury for producing a spreadable $\mathrm{Au}-\mathrm{Hg}$ amalgam paste. After applying the $\mathrm{Au}-\mathrm{Hg}$ paste on the bronze surface, heating induces mercury evaporation, leaving a well-bonded gold-rich layer with a dull appearance, due to the pores generated by mercury evaporation, which, however, is never complete. The fire-gilded layer therefore requires to be "burnished" (i.e. plastically deformed and compacted) by a smooth and hard tool, so as to obtain a shiny surface. The fire-gilding process can be repeated several times, in order to build up the desired thickness [2,3]. Lorenzo Ghiberti's Paradise Door (Baptistery of Florence, 1425-1452) is a well-known example of fire-gilded bronze monument, exposed to the outdoor atmosphere until 1966, when it was damaged by the Arno flood and a careful restoration intervention started [4]. In this case, as in many others such as the horses of Saint Mark's basilica in Venice [5], the growth of corrosion products at the gold/bronze interface lead to blistering or breakup and loss of the gold layer [6,7]. The corrosion products beneath the gold layer, detected in the case of Ghiberti's Paradise Door, were mainly copper oxide, basic sulphates and copper carbonates [8], with minor amounts of chlorides and nitrates [9]. However, copper salts also diffused above the gilded surface, where mineralogical analyses by X Ray Diffraction and IR spectrometry revealed the presence of brochantite, antlerite, paratacamite and copper hydroxyl nitrate [10]. Moreover, deposition of atmospheric particles, containing gypsum, quartz, feldspars, tetra hydrate calcium 
nitrate and carbon, was detected [7,10]. Nitrates may be the result of atmospheric pollution, but may also be due to residues of bronze surface cleaning reagents used by ancient goldsmiths before application of the fire-gilding technique to improve the adhesion of gold on bronze [10].

Degradation of gilded bronze is stimulated by galvanic coupling between bronze and the surface gold layer, much nobler than the substrate from an electrochemical point of view. In order to simulate real exposure conditions of gilded bronze artworks in atmosphere, bronze/gold couples with an interposed corrosion product layer were short circuited by a zero resistance ammeter (ZRA) so as to measure galvanic currents and were exposed to atmospheres with different relative humidity $(\mathrm{RH})$ values and temperatures. Galvanic currents were found to increase at increasing $\mathrm{RH}$ and in the presence of hygroscopic corrosion products. These tests and polarization curves recorded on bronze and gold revealed that gilded bronze artworks are quite unstable systems $[8,11,12]$, whose restoration and conservation are difficult tasks tackled by the application of different strategies. In particular, specific cleaning procedures based on chemical or laser cleaning methodologies have been used [10,13-15]. However, it was found that laser cleaning is not capable to eliminate chlorides, indicating that serious alterations and damages can occur in the long term in the gilding layer if the cleaned gilded bronze pieces were to be exposed to an environment with a high relative humidity [16].

After cleaning, conservation actions must be implemented on gilded bronze artworks to ensure their long-term corrosion protection. Both preventive techniques, such as microclimate control $[8,17]$ ) and use of coatings and inhibitors $[11,18,19]$, were investigated. In order to help microclimate control, specific sensors based on the measurement of galvanic currents in gold/bronze couples were found useful for finding the most suitable climatic parameters to guarantee negligible corrosion rates [20].

As regards protective layers, organosilane coatings attracted a significant research attention in recent years, due to their protective efficiency towards the corrosion of several alloys and some of them were tested on copper and bronze exposed to artificial rain or chloride-containing solutions. Research studies were carried out on octadecyl-trimethoxy-silane [21], glycidoxy-propyltrimethoxy-silane [22] and $\gamma$-aminopropyltriethoxysilane ( $\gamma$-APS) [23]. However, outstanding results were obtained with silanes containing sulphur or mercapto groups, such as bis-[triethoxysilyl-propyl]tetrasulfide [24], 3-mercapto-propyl-triethoxy-silane [25] or 3-mercapto-propyltrimethoxy-silane (PropS-SH) [26-34].

The outstanding protective properties of PropS-SH coatings are connected to the formation of silanol groups $(\mathrm{Si}-\mathrm{OH})$ during silane hydrolysis and to their subsequent condensation in a polymeric 
dense Si-O-Si network. On copper and copper alloys, surface chemisorption of PropS-SH through metal thiolate (Me-S-C) [27] and metal siloxane (Me-O-Si) bonds [35] ensures the desirable adhesion to the metal substrate. Given the affinity of sulphur-containing compounds to transition metals, such as copper and also gold [36-39], PropS-SH was deemed to produce protective coatings for gilded bronze too.

In general, the selection of inhibitors or protective coatings in the Cultural Heritage field requires taking into account the following key points: (i) a basic understanding of the corrosion mechanism and (ii) testing the efficiency and the aesthetical impact of the candidate treatments on representative substrates, which reproduce in a reliable way the complexity of the surfaces found in real conservation interventions. Therefore, in the present work, a fire-gilded bronze was prepared according to ancient methods to mimic the typical microstructure and morphology of fire-gilded bronzes, both as regards the alloy and the gold layer. In the first step of the work, a detailed investigation of the corrosion process of gilded bronze (so as to contribute to key point (i)) was achieved by collecting polarization resistance measurements and polarization curves, after different exposure times during alternated immersion in concentrated synthetic acid rain.

Subsequently, in the second step, gilded bronze was aged in conditions more closely simulating different outdoor exposures (wet\&dry and dropping tests [40,41], simulating exposure to stagnant rain and to runoff, respectively). The aim of this second step was both to reproduce the typical corrosion features of real gilded bronzes (i.e. craters at the interface between gold and bronze) in both sheltered and unsheltered areas of monuments and to test the efficiency of a protective coating in environmental representative conditions (key point (ii)). The tested protective coating was obtained from 3-mercapto-propyl-trimethoxy-silane (PropS-SH), selected on the basis of previous electrochemical tests and accelerated ageing tests performed on the same bronze alloy as the gilded bronze substrate $[31,33]$.

\section{Experimental}

\subsection{Material}

The composition of the studied bronze, cast in stone moulds and then fire-gilded, is similar to those of Renaissance artefacts $(91.9 \mathrm{Cu}, 2.9 \mathrm{Zn}, 2.4 \mathrm{Sn}, 1.0 \mathrm{~Pb}, 0.8 \mathrm{Sb} \mathrm{wt} \%)$. The bronze specimens showed a dendritic microstructure of cored $\alpha$-Cu solid solution, typical of as-cast bronzes, with $\mathrm{Sb}$ - and $\mathrm{Sn}$ rich phases in the interdendritic spaces, as described in a previous work [31]. Also Pb globules were present in the interdendritic spaces. Residual porosity and shrinkage cavities were uniformly distributed in the samples. 
Fire-gilding was carried out after mechanical grinding with $\mathrm{SiC}$ abrasive paper (180 grit) and nitric acid pickling of the cast bronze surface. The pickled surface was covered with $\mathrm{Au}-\mathrm{Hg}(1: 8)$ amalgam paste (according to the recipe by Benvenuto Cellini in his treatises on goldsmithing and sculpture (1568) [42]) and then heated by a free flame, so as to vaporize Hg. Subsequently, the gilded surface was burnished by an agate tool (using olive oil as a lubricant), in order to densify the porous layer and produce a smooth and shiny surface. Before testing, the specimen surface was washed with deionized water and degreased with acetone.

Protective coatings based on a silane-based inhibitor, selected on the basis of previous works $[31,33]$, were deposited on as-gilded bronze coupons. In order to deposit the organosilane film, the coupons were completely immersed for $1 \mathrm{~h}$ into a hydrolysed silane solution (90/5/5 v/v ethanol/water/PropS-SH) at $\mathrm{pH} 4$ ( $\mathrm{pH}$ adjusted by sulphuric acid addition). A room temperature curing period of 10 days was always adopted before exposing the coated specimens to the aggressive environment.

The lateral non-gilded surfaces of uncoated and coated specimens were protected by epoxy resin, to avoid corrosion and metal release from non-gilded areas. In the case of specimens for electrochemical tests, a threaded copper bar was screwed on a lateral specimen side to ensure the necessary electrical contact for electrochemical tests and, after screwing, it was protected again from the aggressive environment by epoxy resin.

\subsection{Electrochemical tests}

Electrochemical tests were performed on both gilded and bare reference bronze specimens to get information about the characteristics and evolution of the corrosion processes on these materials. The reference bronze alloy had composition $(87.3 \mathrm{Cu}, 3.5 \mathrm{Zn}, 5.3 \mathrm{Sn}, 2.5 \mathrm{~Pb}, 1.0 \mathrm{Ni}, 0.4 \mathrm{Sb}$ wt $\%)$ and microstructure similar to that of the gilded substrate. The specimens were exposed under wet\&dry conditions to a tenfold concentrated synthetic acid rain (Table 1, $\mathrm{pH} 3.3$ ), formulated according to the composition of a mixture of natural acid rains collected in Bologna (Italy) [43]. The use of the concentrated solution with a relatively high electrical conductivity (about $350 \mu \mathrm{Scm}^{-1}$ ) aimed at reducing the ohmic drop and facilitated electrochemical tests such as polarization curve recording. The concentrated solution can possibly slightly accelerate the corrosion of bronze and gilded bronze with respect to plain synthetic rain because of its lower $\mathrm{pH}$ value (3.3 instead of 4.3), but it should not modify the nature of the stable corrosion products on the studied materials, as suggested by the Pourbaix diagram of copper, calculated in the absence and in the presence of chlorides [44,45]. As a consequence, it should not significantly alter the corrosion mechanism. 
The wet\&dry test simulated the condition of rainwater stagnation through alternating immersions during which the bronzes were periodically dipped into the aggressive solution. The total duration of a wet and dry corrosion cycle was $1 \mathrm{~h}$, corresponding to $20 \mathrm{~min}$ of immersion and $40 \mathrm{~min}$ of emersion. A time of about $20 \mathrm{~min}$ for the samples to reach a constant weight was measured during the setup of the test, so a Time Of Wetness (TOW) of 40 min was assumed to correspond to an hourly cycle [40]. A total TOW of 10 days was adopted, corresponding to 15 days of overall test time. The solution was weekly renewed.

The electrochemical behaviour of the studied materials was monitored by collecting the corrosion potentials $\left(E_{c o r}\right)$ and the polarization resistance $\left(R_{p}\right)$ values on samples extracted at intervals from the wet\&dry device and transferred in a traditional three electrode electrochemical cell. The first measurement was always performed after $1 \mathrm{~h}$ of immersion, when a sufficiently stable $E_{c o r}$ value was achieved. Afterwards, the described wet\&dry cycles started. $R_{p}$ values were measured by applying Electrochemical Impedance Spectroscopy (EIS), in order to allow for compensation of the solution resistance $\left(R_{S}\right)$ between the working and reference electrodes The spectra were obtained by a PAR 2273 potentiostat/Frequency Response Analyzer (FRA)/galvanostat under the following experimental conditions: 20 min conditioning time, sufficient to get $E_{c o r}$ stability; $\pm 10 \mathrm{mV}$ rms alternating potential signal; $1 \mathrm{MHz}-1 \mathrm{mHz}$ frequency range; 10 frequencies/decade. Under wet\&dry conditions, the Nyquist plots of the EIS spectra recorded on bronze and gilded bronze usually exhibited a single capacitive depressed arc. Only within 1 or 2 days of TOW, bronze exhibited two capacitive time constants as shown by Figure 1 which compares the spectra achieved on bronze (after short exposure times: TOW of $1.5 \mathrm{~d}$ ) and gilded bronze (e.g. at TOW of $10.0 \mathrm{~d}$ ). The Figure also shows that $R_{p}$ was estimated by circle fitting the capacitive arc (or the low frequency arc, in the presence of two capactive time constants) and corresponded to the low frequency intercept of the circle with the real axis, after subtraction of the $\mathrm{R}_{\mathrm{s}}$ value (Figure 1). Ohmic drop-compensated polarization curves were recorded (again by PAR 2273) after both $1 \mathrm{~h}$ immersion and 10 days of TOW in concentrated acid rain, on different electrodes. The potential scan always started from $E_{c o r}$ and the potential scan rate was $0.1667 \mathrm{mV} \mathrm{s}^{-1}$.

All the tests were carried out at least in duplicate and representative curves were considered. The potentials quoted in the text are referred to the Saturated Calomel Electrode (SCE).

\subsection{Corrosion attack characterization and metal release during simulated atmospheric exposures}

Uncoated gilded bronze specimens were exposed to synthetic rain $(\mathrm{pH}=4.3)$ under both wet\&dry and dropping conditions, again with a total TOW of 10 days (short-term ageing), with the aim to 
evaluate the extent and morphology of the corrosion attack under conditions more similar to natural atmospheric exposures.

While the wet\&dry test (performed as previously reported in \$2.2) mimics the condition of rainwater stagnation, the dropping tests simulates unsheltered exposure to rainwater (runoff conditions). In this case, the rain solution was periodically dropped onto $45^{\circ}$ inclined specimens and collected. In particular, cycles of 2-days dropping/1-day drying and 3-days dropping/1-day drying were alternated. Wet\&dry and dropping tests were carried out at least in triplicate and the ageing solutions were collected. The ageing solution samples were stored and analysed for the metal content $(\mathrm{Cu}, \mathrm{Pb})$ by Graphite Furnace Atomic Absorption Spectrometry (GF-AAS), according to the method described in [40,41].

Finally, dropping tests with a longer TOW (30 days) were performed, in order to test the influence of the gilding layer and the protective efficiency of the organosilane coating under the exposure conditions which proved to be the most severe ones (runoff). Both the metal samples and the ageing solution were characterized. The morphology of the gilded surfaces was studied by 3D-Digital Microscopy and Scanning Electron Microscopy (SEM). At the end of the exposure, both conventional metallographic techniques (by cold mounting) and Focused Ion Beam (FIB) milling (by a FEI Dual Beam Strata 235M System, combining a $\mathrm{Ga}^{+}$ion beam and a thermal field emission SEM, working at coincidence on the sample) were used, so as to prepare cross sections and investigate the corrosion layers at the gold/bronze interface. When cross-sections were prepared by FIB, a protective Pt-C layer was deposited on top of the gilded surface before milling, so as protect surface features.

The composition of the corrosion products was identified by a hyphenated system SEM/EDSRaman SCA (Scanning Electron Microscopy with Energy Dispersive Spectroscopy and Raman microprobes, Structural and Chemical Analyser, $\lambda=514.5 \mathrm{~nm}$, full power: $50 \mathrm{~mW}$ ). Colour variations due to coating and/or exposure were assessed by Reflectance Spectrophotometry (Datacolor CHECK II, illuminant D65, $10^{\circ}$ observer, beam of diffuse light: $6 \mathrm{~mm}$, specular component excluded-SCE) and colour data were elaborated in the CIELAB colour space. In this space, $L^{*}, a^{*}$ and $b^{*}$ correspond to the lightness, the red/green and the yellow/blue coordinates respectively, and the total colour difference is represented by the $\Delta E^{*}$ parameter: $\Delta E^{*}=$ $\sqrt{ }\left(\Delta L^{* 2}+\Delta a^{* 2}+\Delta b *^{2}\right)$. Three different points were selected on each specimen and 3 measurements were collected at each point before and after coating and/or exposure.

\section{Results and discussion}




\subsection{Characterization of as-supplied gilded bronzes}

The as-supplied gilded samples (before exposure tests) show two main surface morphologies (Fig. 2a), as observed also by other authors [3]: smooth areas (where the burnishing procedure successfully compacted the gilded layer after $\mathrm{Hg}$ evaporation) and porous areas (where the depth of the grooves on the bronze surface, due to mechanical polishing before gilding, was too high to allow full densification of the gilded layer by burnishing). The correlation between surface morphology and compactness of the gilded layer was clearly confirmed by FIB cross-section observations, as shown in Figure 2b,c.

A higher-magnification detail of the gilded layer, produced after FIB milling by ion channelling contrast, is reported in Figure 3. Ion channelling contrast occurs because $\mathrm{Ga}^{+}$ions travel furthest along crystallographic directions aligned with the incident ion beam, yielding reduced secondary electron emission from the surface and hence darker regions in the image [46]. Owing to ion channelling contrast, it is possible to highlight the microstructure of both the gold layer and the outermost layer of the bronze substrate. The microstructure of the gold layer mostly consists of annealing twins, due to the recrystallization process, which takes place during heating of the firegilded layer to induce mercury evaporation.

A few pores and cracks are also clearly visible in the gold layer. These morphological features have a key role in influencing the corrosion behaviour of the fire-gilded bronze, because the presence of pores and cracks allows the access of condensed water or rain and induces galvanic corrosion of the less noble bronze substrate, in the gold/bronze galvanic couple.

Furthermore, the most superficial layer of the bronze substrate displays a microstructure with very fine, strain-hardened grains, elongated in the direction of material flow due to mechanical polishing before gilding. The strain-hardened bronze (SHB) layer with fine elongated grains in Figure 3 is less than $2 \mu \mathrm{m}$ thick, however it may have a remarkable influence on corrosion of the gilded bronze [47], because it is located just below the gold layer and it has a much more reactive microstructure than the dendritic bulk alloy.

EDS analyses in cross-section of both the gold layer and the underlying bronze showed that $\mathrm{Cu}-\mathrm{Au}$ interdiffusion occurred, as observed also by other authors [48]: at a distance of about $5 \mu \mathrm{m}$ from the gold/bronze interface, Au concentrations as high as 20 wt.\% were measured, whilst in the Au-rich layer (that usually contains also $\mathrm{Hg}$, ranging from 7 to 9 wt.\%), $\mathrm{Cu}$ was detected with concentrations up to $10 \mathrm{wt} \%$. Even though these localised EDS concentration values may be overestimated due to polishing artefacts, $\mathrm{Cu}-\mathrm{Au}$ interdiffusion, due to heating required by the firegilding process, is not unexpected, as $\mathrm{Cu}$ and $\mathrm{Au}$ are reported to intermix readily even at 
temperatures as low as $150^{\circ} \mathrm{C}$ [49]. EDS X-ray maps also show the presence of $\mathrm{Pb}$ in the gold layer, but care must be taken in the interpretation of this result, because of tailing phenomena involving the peaks of $\mathrm{Pb}(\mathrm{M} \alpha=2.34 \mathrm{keV}), \mathrm{Hg}(\mathrm{M} \alpha=2.19 \mathrm{keV})$ and $\mathrm{Au}(\mathrm{M} \alpha=2.12 \mathrm{keV})$. Further investigations by XPS on this issue are in progress. Also detectable amounts of $\mathrm{N}$ can be measured by EDS in fire-gilded samples, due to the use of nitric acid as a pickling agent before the application of the $\mathrm{Au}-\mathrm{Hg}$ amalgam paste.

As regards the aesthetical appearance, the gilding layer $\left(L^{*} 55 \pm 3, a^{*}-0.1 \pm 0.7, b^{*} 27 \pm 1\right)$ shows a relatively high internal variability, with a maximum $\Delta E^{*}$ of 4.5 within the same specimen, mainly ascribable to lightness variations $\left(\Delta L^{*}\right)$. As a comparison, a 3 unit difference in the CIELAB colour space can be assumed as general limit of perceptibility also for cultural heritage metals [50-52].

\subsection{Electrochemical tests}

Figure 4 shows the $R_{p}$ and $E_{c o r}$ values collected on both gilded bronze and bare bronze (investigated as reference material), during wet\&dry tests in concentrated acid rain up to 10 days of TOW. For both materials, corrosion involved oxidation of bronze and oxygen reduction but, in the case of the gilded material, the contact between the aggressive solution and the bronze substrate occurred only through the pores of the gold layer, which acted as a cathodic area sustaining most part of the oxygen reduction. Figure 4 shows that, on gilded bronze, low $R_{p}$ values close to $1 \mathrm{k} \Omega \mathrm{cm}^{2}$ were detected after $1 \mathrm{~h}$ immersion. Then these values increased with TOW up to about $6 \mathrm{k} \Omega \mathrm{cm}^{2}$. The corresponding $E_{c o r}$ values became slightly less positive as they shifted from about $0.13 \mathrm{~V}_{\mathrm{SCE}}$, after $1 \mathrm{~h}$ immersion, to about 0.09 after 10 days of TOW. Under the same ageing conditions, bare bronze electrodes exhibited an opposite dependence of $R_{p}$ and $E_{c o r}$ upon TOW. In fact, during the first 2 days, $R_{p}$ values decreased from $6 \mathrm{k} \Omega \mathrm{cm}^{2}$ to values of about one order of magnitude lower and then remained more or less constant, while $E_{\text {cor }}$ quickly ennobled from -0.10 up to $0.02 \mathrm{~V}_{\mathrm{SCE}}$ and then persisted unaltered, until the end of the test.

Figure $5 \mathrm{a}$ and $\mathrm{b}$ shows polarization curves recorded on bronze and gilded bronze, respectively. After $1 \mathrm{~h}$ immersion, passive conditions were found on bronze, with corrosion currents $\left(i_{c o r}\right)$ of about $1 \mu \mathrm{A} \mathrm{cm}^{-2}$ (Figure $5 \mathrm{a}$ ). Only at potentials more positive than $0.01 \mathrm{~V}_{\mathrm{SCE}}$, the passive film breakdown was possible and quick bronze dissolution occurred. At potentials close to $E_{c o r}$, the cathodic reaction of oxygen reduction on bronze was under activation control and no clear limiting current was reached in the potential range investigated. However, after only 0.5 days of TOW under wet\&dry conditions, the cathodic polarization curve of bronze shifted towards higher currents and resulted under mass transport control, inducing an $E_{c o r}$ ennoblement up to the breakdown potential 
of the surface film. Therefore, after this exposure time, a low anodic overvoltage was found in proximity of $E_{c o r}$ and $i_{c o r}$ increased of about one order of magnitude. After a longer exposure time to the same conditions (10 days of TOW), the polarization curves did not change significantly, beside a slight decrease in the cathodic currents close to $E_{c o r}$. These polarization curves were in agreement with the $E_{c o r} / R_{p}$ time evolution and suggested that the air-formed oxide film on bronze exhibited a low catalytic activity towards the oxygen reduction reaction and was relatively protective. However, the integrity of this film was quickly impaired by the evolution and dissolution of the film ensued during wet\&dry exposure to the acidic electrolyte [40]. This film did not hinder the cathodic reaction and induced a low anodic overvoltage. The protectiveness of this irregular surface film did not vary significantly with TOW.

In agreement with Figure 4, after $1 \mathrm{~h}$ immersion, the gilded bronze exhibited a quite different behaviour (Figure $5 \mathrm{~b}$ ), with much nobler $E_{\text {cor }}\left(+0.13 \mathrm{~V}_{\mathrm{SCE}}\right)$ and higher $i_{\text {cor }}$ (about $20 \mu \mathrm{A} \mathrm{cm} \mathrm{cm}^{-2}$ ) values than those recorded on bronze after the same exposure period. These features were the consequence of a fast cathodic reaction established on the surface of the gold layer. In comparison, the oxygen reduction, evaluated from the current density normalized by the geometrical area, on a gold foil with a $1 \mu \mathrm{m}$ finished surface, was much slower (Figure $5 \mathrm{~b}$ ), because the exposed area was much smaller than that of gold on gilded bronze, where a remarkable micro-porosity of the gilded layer increases the real exposed surface (Figure 2a,c). The cathodic polarization curve on gold foil is similar to that previously obtained by Mazza et al. in $0.2 \mathrm{M} \mathrm{Na}_{2} \mathrm{SO}_{4}$ at $\mathrm{pH} 5$ [11]. On gilded bronze, the porous non-compacted regions of the gold layer permitted the easy electrolyte penetration and a consequent large cathodic region area. Figure $5 \mathrm{~b}$ also shows that the substrate oxidation was characterized by a high anodic overvoltage, because its rate was controlled by the slow diffusion of soluble corrosion products of bronze through the pores of the gold layer. Of course, on the reference polished gold foil the anodic current densities were negligible in comparison and were linked to the faradic reaction of double layer charging. At longer exposure periods (10 days of TOW, Figure 5b), a significant decrease in the cathodic currents was observed which caused a less noble $E_{\text {cor }}\left(0.090 \mathrm{~V}_{\mathrm{SCE}}\right)$ and one order of magnitude lower $i_{\text {cor }}$ value, with respect to those recorded after $1 \mathrm{~h}$ immersion. These observations are in good agreement with $R_{p}$ and $E_{c o r}$ time trends of Figure 4. This phenomenon is likely connected to the precipitation of bronze corrosion products inside the gilded layer pores. These precipitates hindered both the transport of oxidized species in solution and the oxygen reduction, because they limited the access of the electrolyte in the gold layer pores and diminished the cathodic surface area. 


\subsection{Gilded bronze after simulated outdoor exposure}

Cross-section images (SE-SEM) of fire-gilded bronze after short-term exposure to acid rain by wet\&dry and dropping tests $(\mathrm{TOW}=10 \mathrm{~d})$ are compared in Figure 6. Localised corrosion damages in the form of craters were visible at the gold/bronze interface, and generally craters were present in correspondence with defective areas of the gilded layer. However, the size and number of craters were affected by the exposure conditions: wet\&dry testing generated a limited number of very small craters, whilst dropping tests induced a higher number of bigger craters.

In order to quantify the aggressiveness of the different exposure conditions, analyses of the ageing solutions were performed to determine the extent of metal release in synthetic rain during both types of tests (Table 2). After $10 \mathrm{~d}$ of TOW under wet\&dry conditions, copper and lead release from bare bronze was higher than that from gilded bronze, indicating that, as already observed on the basis of electrochemical measurements in concentrated solution, the dissolution of the bronze substrate was progressively hindered by corrosion product formation in the gilded layer. The lower metal release due to the presence of the gilded layer was also observed after $10 \mathrm{~d}$ of dropping (Table 2), with a more remarkable difference between gilded and bare bronze due to the higher severity of the dropping test (discussed below). As an example, during wet\&dry test, copper release from bare bronze was about 1.7 times higher than that from gilded bronze, while it was about 40 times higher in the case of the dropping test. Table 2 also shows that, in the dropping test, the amount of dissolved ions from both materials is about one order of magnitude higher than in the wet\&dry test. The higher severity of the dropping test in comparison to wet\&dry was previously observed also in the case of conventional bronzes [40] and was attributed to the presence of important runoff phenomena. Therefore, in this work, long-term ageing tests were only performed under the harsher dropping test conditions.

A representative cross section BSE image of fire-gilded bronze exposed for 30 days of TOW to runoff tests in acid rain is shown in Figure 7a, together with the X-ray maps of elemental distribution obtained by EDS (Fig. 7b-e). A comparison of the craters in the images in Figure 6b and 7 shows that the crater size increases with increasing TOW (from 10 to 30 days), as expected. Furthermore, in samples aged by long-term dropping tests, the size, morphology and distribution of craters at the gold/bronze interface are comparable to those of real monuments, such as Ghiberti's Paradise Door [6].

SEM/EDS analysis of the craters indicated the presence of alternated layers of $\mathrm{Cu}$ and $\mathrm{Sn}$ corrosion products, where $\mathrm{O}$ (Fig. 7a,c) is the main environmental aggressive element and Sn-enrichement is clearly visible (Fig. 7a,e). Moreover, oxygen trapping within the gilded layer suggested that, also in 
the case of runoff exposure, the corrosion products encrustations in the gilded layer pores might reduce the substrate corrosion rate, as indicated by electrochemical tests in wet\&dry conditions. Micro-Raman analysis of the crater area (Fig. 8) showed the presence of cuprite as the main corrosion product (with minor contributions from the mounting resin). Alternated $\mathrm{SnO}_{2} / \mathrm{Cu}_{2} \mathrm{O}$ layers were also detected by other authors in conventional bronze monuments, after natural exposure to runoff and in archaeological tin bronzes. During exposure to runoff, they were attributed to a patina destabilization due to repetitive $\mathrm{pH}$ decreases connected to the rainfall, triggering not only a decuprification process, but also a selective zinc dissolution with a relative enrichment of the external layer in Sn-containing species [53-56]. In the case of archaeological artefacts, they were mainly ascribed to interdiffusion of metal ions from the alloy and aggressive species from the environment (the so-called Liesegang phenomena) [57-60]. Also environmental changes in burial conditions, such as seasonal temperature fluctuations, rainfall fluctuations and change in soil corrosivity, were reported to contribute to this phenomenon [61].

Localised EDS analyses, carried out on FIB milled cross-sections of the same crater as that in Fig. 7, allowed the detection of $\mathrm{Cl}$ (Fig. 9a,b) in the lower layers of corrosion products, near the bronze/corrosion interface, as typically observed in bronzes exposed to $\mathrm{Cl}$-containing environments [62,63]. Furthermore, residual $\mathrm{Pb}$-rich areas around the empty spaces (generated by preferential dissolution of anodic Pb-rich globules [33]), were detected (Fig. 9c,d).

Due to the exposure conditions (i.e. runoff), dissolved metals passing through the gilding layer were leached away. Even if no corrosion products were detected above the gold layer, a slight but significant colour variation (Table 3) together with an increase in the internal colour variability $\left(\Delta E^{*}\right.$ max within a same sample equal to 6.5 ) were recorded with respect to unexposed samples, indicating an alteration of the surface.

As for bare bronze, metal release through the gilding layer (Fig. 10b,c), as well as mass decrease (Fig. 10a), tended to occur linearly during runoff tests $\left(r^{2}>0.99\right.$ for bare bronze and $>0.96$ for gilded bronze), but the rates were always one order of magnitude lower than those recorded for bare bronze. Specifically, for bare bronze, mass decrease, $\mathrm{Cu}$ and $\mathrm{Pb}$ cumulative release at 30 days of TOW were $6.0( \pm 6 \%) \mathrm{mg} \mathrm{cm}^{-2}, 5233( \pm 15 \%) \mu \mathrm{g} \mathrm{cm}^{-2}$ and $143( \pm 20 \%) \mu \mathrm{g} \mathrm{cm}^{-2}$, respectively.

On the basis of cumulative metal release data, the inhibiting efficiency in terms of metal release $\left(\eta_{M}\right)$ can be defined [33] as follows:

$\eta_{M}=\frac{M_{s o l, N C}-M_{s o l, C}}{M_{s o l, N C}} x 100$ 
where: $M$ is the metal (e.g. $\mathrm{Cu}), M_{\text {sol }}$ is the amount of metal leached in the ageing solution $\left(\mu \mathrm{g} \mathrm{cm}^{-}\right.$ ${ }^{2}$ ); the subscript $N C$ refers to non-coated and $C$ to coated bronze samples. $\eta_{M}$ is $100 \%$ if no metal is released from the coated bronze and $0 \%$ if the coated bronze releases as much metal as the noncoated one.

Considering the gold layer as a coating and bare bronze as a reference (Table 4), $\eta_{M}$ calculated by equation (1) shows that gilding afforded a good protection to bronze in term of metal release, as both $\mathrm{Cu}$ and $\mathrm{Pb}$ dissolution at 30 days of TOW were reduced by 82 and $88 \%$ respectively. Gravimetric measurements are in agreement with this finding, as gilding reduced mass decrease by $78 \%$.

\subsection{PropS-SH-coated gilded bronze after simulated outdoor exposure}

Long-term dropping tests were also selected to assess PropS-SH coating protectiveness. Figure 11a,b reports a comparison of as-gilded and PropS-SH coated gilded surfaces, that clearly show the ability of PropS-SH to fill up the grooves and porous areas of the gold layer. In general, the deposition of PropS-SH on as-gilded bronze led to a significant decrease of the localized corrosion attacks by comparison to uncoated gilded bronze (Fig. 11c): craters are completely absent in the cross-sections of PropS-SH coated samples (Figure 11d and 12a). Only a very small crater can be seen in Figure 12b. The FIB cross-section images in Figure 12 also show quite clearly the accumulation of PropS-SH (dark grey layer on top of the whitish gold layer) in the grooves and porous areas, where the gold layer was not compacted by burnishing. Probably, the accumulation of PropS-SH contributed to seal the defects and discontinuities, mostly located in grooves and porous areas of the gold layer, thus helping to enhance the corrosion resistance.

As regards colour, the application of PropS-SH on the as-gilded bronze tended to uniform the appearance of the surface, by reducing the internal colour variability ( $\Delta E^{*}$ max within a same sample equal to 2.3) and induced a slightly perceptible colour variations mainly due to an increase in lightness and a decrease in the red component $\left(a^{*}\right)$ (Table 3). PropS-SH coating also reduced the total colour variation $\left(\Delta E^{*}\right)$ occurring on the samples when exposed to dropping test from $5 \pm 2$ to $3 \pm 2$. The latter value, even if close to the perceptibility threshold, is difficult to detect by eye, being the colour change of the coating well balanced among the three coordinates (Table 3). Furthermore, exposure to dropping test, unlike that for uncoated specimens, did not significantly change the internal variability of the coated samples ( $\Delta E^{*}$ max within a same sample equal to 2.8 ). 
The protective efficiency of PropS-SH was also assessed by gravimetric measurements and solution analysis. Data plotted in Fig. 10a as a function of exposure time (TOW) show that the presence of PropS-SH limited the mass decrease of gilded bronze of about 50\%, by comparison to the uncoated samples. Cumulative metal release data in Fig. 10b,c demonstrated that the organosilane coating was able to limit $\mathrm{Cu}$ release, but it did not display beneficial effects on $\mathrm{Pb}$ release from the coated gilded bronze. A scarce inhibition of $\mathrm{Pb}$ ion release under runoff conditions was already detected in the case of non-gilded pre-patinated bronze coated by PropS-SH [33]. The reasons for this phenomenon are currently under investigation but not yet elucidated. They could be connected to a more significant chelating effect of the silane functional groups towards copper than lead ions, as confirmed by the more significant bonding and protective effect exerted by PropS-SH on pure copper than on pure lead [33]. However, an important role in this phenomenon could also be played by complex $\mathrm{pH}$ and composition variations expected in the solution at the metal/coating interface, due to restricted ion diffusion. These variations could alter the relative solubility of the different cations. In particular, dissolved copper cations could precipitate on the active cathodic centers on gold due to local $\mathrm{pH}$ increase, while lead cations could be more easily dissolved through the coating, due to the wider $\mathrm{pH}$ range of stability of lead cations, as suggested by Pourbaix diagrams [44].

On gilded bronze, the inhibiting efficiency of $\mathrm{Cu}$ release ( $\eta_{C u}$ eq.1), afforded by PropS-SH coating was calculated as $63 \%$ (Table 4). So, the application of PropS-SH increased the ability of the gilding layer to limit $\mathrm{Cu}$ release from $82 \%$ to $93 \%$ (Table 4) and to reduce mass decrease from $78 \%$ to $90 \%$.

Further investigations will focus on the application of organosilane-based coatings on fire-gilded bronze, pre-patinated by accelerated ageing in runoff conditions, so as to mimic the conditions of conservation interventions on ancient gilded bronzes.

\section{Conclusions}

The main results of this investigation on fire-gilded bronze corrosion, based on simulated outdoor exposures, can be summarised as follows:

- The electrochemical tests on gilded bronze during wet\&dry exposure show a decrease of the corrosion rate with time. This is due to local accumulation of insoluble bronze corrosion products, which tend to obstruct the gold layer pores, so limiting galvanic corrosion of the bronze substrate as well as $\mathrm{Cu}$ and $\mathrm{Pb}$ release. By comparison, higher corrosion rates are detected on bare bronze, which are more or less constant after 1 day of TOW. 
- Both wet\&dry (simulating exposure to stagnant rain in sheltered areas of the monument) and dropping tests (simulating exposure to runoff in unsheltered areas) induce corrosion at the gold/bronze interface. Dropping tests lead to the most severe corrosion damages, with deeper craters and higher metal release from underlying bronze.

- Long-term dropping tests (TOW=30 days) are able to reproduce a corrosion morphology comparable to those observed in reference historical fire-gilded bronzes (craters and blisters at the gold/bronze interface)

- Dropping tests can be used for assessing the protectiveness of coatings.

- The PropS-SH organosilane coating applied on gilded bronze is able to limit mass decrease and $\mathrm{Cu}$ release, but it does not display any beneficial effects on $\mathrm{Pb}$ release, as already found in the case of PropS-SH coated bronze.

\section{Acknowledgments}

This research has been financially supported by PRIN 2009 MIUR Funds (Italy). The financial support of Emilia-Romagna Region, Italy (POR-FESR funds) is gratefully acknowledged. The authors wish to thank: Mr. Alessandro Pacini for producing fire-gilded bronzes according to ancient recipes (https://sites.google.com/site/archeometallurgia/). Dr. Iuri Boromei, at Dept. Industrial Engineering, University of Bologna, for his valuable help in sample preparation and for SEM/EDS investigations. Dr. Gian Carlo Gazzadi at CNR NANO, Modena, for FIB-FEG/SEM analyses. Ms. Benina Lenza, Ms. Serena Bassini, Ms. Marie Cordier and Mr. Victor Andrei Oancea for their contributions to the experimental work. Dr. Simone Porcinai at Opificio delle Pietre Dure, Florence, for valuable discussions on corrosion problems and conservation interventions on Ghiberti's Paradise Door.

\section{References}

[1] E. Darque-Ceretti, M. Aucouturier, Gilding for matter decoration and sublimation. A brief hisotry of the artisanal technical know-how, Int. J. Conserv. Sci. 4 (2013) 647-660.

[2] W.A. Oddy, Gilding of metals in the old world, in: S. La Niece, P. Craddock (Eds.), Met. Plat. Patination, Butterworth-Heinemann, Oxford, UK, 1993: pp. 171-181.

[3] K. Anheuser, The Practice and Characterization of Historic Fire Gilding Techniques, JOM. (1997) $58-62$.

[4] VV.AA., The Gates of Paradise. Lorenzo Ghiberti's Renaissance Masterpiece, High Museum of Art, Altanta, in association with Yale University Press, New Haven and London, 2007. 
[5] V. Alunno Rossetti, M. Marabelli, Analyses of the patinas of a gilded horse of St Mark's Basilica in Venice: corrosion mechanisms and conservation problems, Stud. Conserv. 21 (1976) 161-170.

[6] E. Mello, The gilding of Lorenzo Ghiberti's "Doors of Paradise," Gold Bull. 19 (1986) 123-126. doi:10.1007/BF03214652.

[7] P. Fiorentino, M. Marabelli, M. Matteini, A. Moles, The condition of the "Door of Paradise" by L. Ghiberti. Tests and proposals for cleaning, Stud. Conserv. 27 (1982) 145-153.

[8] G. Alessandrini, G. Dassù, P. Pedeferri, G. Re, On the conservation of the Baptistery doors in Florence, Stud. Conserv. 24 (1979) 108-124.

[9] S. Siano, R. Salimbeni, The Gate of Paradise: Physical optimization of the laser cleaning approach, Stud. Conserv. 46 (2001) 269-281.

[10] A. Giusti, M. Matteini, The gilded bronze Paradise Doors by Ghiberti in the florence baptistery: Scientific investigation and problems of restoration, in: Int. Conf. Met. Restor., 1997.

[11] B. Mazza, P. Pedeferri, G. Re, D. Sinigaglia, Effectiveness of some inhibitors on the atmospheric corrosion of gold plated bronzes, in: 4th Eur. Symp. Corros. Inhib., Annal. Univ. Ferrara, Ferrara, Italy, 1975: pp. 552-563.

[12] B. Mazza, P. Pedeferri, G. Re, D. Sinigaglia, Behaviour of a galvanic cell simulating the atmospheric corrosion conditions of gold plated bronzes, Corros. Sci. 17 (1977) 535-541.

[13] S. Siano, R. Salimbeni, R. Pini, A. Giusti, M. Matteini, Laser cleaning methodology for the preservation of the Porta del Paradiso by Lorenzo Ghiberti, J. Cult. Herit. 4 (2003) 140s-146s. doi:10.1016/S1296-2074(02)01138-X.

[14] M. Matteini, C. Lalli, I. Tosini, A. Giusti, S. Siano, Laser and chemical cleaning tests for the conservation of the Porta del Paradiso by Lorenzo Ghiberti, J. Cult. Herit. 4 (2003) 147-151. doi:10.1016/S1296-2074(02)01190-1.

[15] H. Lee, N. Cho, J. Lee, Applied Surface Science Study on surface properties of gilt-bronze artifacts , after Nd:YAG laser cleaning, Appl. Surf. Sci. 284 (2013) 235-241.

doi:10.1016/j.apsusc.2013.07.087.

[16] G. Festa, C. Andreani, M.P. De Pascale, R. Senesi, G. Vitali, S. Porcinai, et al., A nondestructive stratigraphic and radiographic neutron study of Lorenzo Ghiberti's reliefs from paradise and north doors of Florence baptistery, J. Appl. Phys. 106 (2009) 0749091-00749095. doi:10.1063/1.3204514.

[17] S. Goidanich, L. Toniolo, D. Matera, B. Salvadori, S. Porcinai, A. Cagnini, et al., Corrosion evaluation of Ghiberti's "Porta del Paradiso" in three display environments, in: P. Mardikian, C. Chemello, C. Watters, P. Hull (Eds.), Int. Conf. Met. Conserv. Interim Meet. Int. Counc. Museums Comm. Conserv. Met. Work. Gr., Clemson University, South Carolina, USA, Charleston, South Carolina, USA, 2010: pp. 151-159.

[18] M. Marabelli, The monument of Marcus Aurelius: Research and conservation, in: D.A. Scott, J. Podany, B. Considine (Eds.), Anc. Hist. Met. Conserv. Sci. Res., 1994.

[19] C. Giavarini, M.L. Santarelli, Gli studi per la protezione del Marco Aurelio, Mater. E Strutt. 6 (1996) 137-146. 
[20] S. Goidanich, D. Gulotta, L. Brambilla, R. Beltrami, P. Fermo, L. Toniolo, Setup of galvanic sensors for the monitoring of gilded bronzes, Sensors (Basel). 14 (2014) 7066-7083. doi:10.3390/s140407066.

[21] F. Zucchi, V. Grassi, a. Frignani, G. Trabanelli, C. Monticelli, Octadecyl-trimethoxy-silane film formed on copper in different conditions, Mater. Chem. Phys. 103 (2007) 340-344. doi:10.1016/j.matchemphys.2007.02.050.

[22] F. Deflorian, S. Rossi, L. Fedrizzi, M. Fedel, Integrated electrochemical approach for the investigation of silane pre-treatments for painting copper, Prog. Org. Coatings. 63 (2008) 338-344. doi:10.1016/j.porgcoat.2008.03.005.

[23] C. Rahal, M. Masmoudi, M. Abdelmouleh, R. Abdelhedi, Progress in Organic Coatings An environmentally friendly film formed on copper : Characterization and corrosion protection, Prog. Org. Coatings. 78 (2015) 90-95. doi:10.1016/j.porgcoat.2014.09.018.

[24] H. Zhu, S. Chen, Y. Chen, Z. Zhu, Y. Yin, Investigation of the corrosion resistance of n-tetradecanoic acid and its hybrid film with bis-silane on copper surface in seawater, J. Mol. Struct. 928 (2009) 4045. doi:10.1016/j.molstruc.2009.03.009.

[25] M.A. Chen, X. Bin Lu, Z.H. Guo, R. Huang, Influence of hydrolysis time on the structure and corrosion protective performance of (3-mercaptopropyl)triethoxysilane film on copper, Corros. Sci. 53 (2011) 2793-2802. doi:10.1016/j.corsci.2011.05.010.

[26] R.J. Tremont, D.R. Blasini, C.R. Cabrera, Controlled self-assembly of mercapto and silane terminated molecules at $\mathrm{Cu}$ surfaces, J. Electroanal. Chem. 556 (2003) 147-158. doi:10.1016/S00220728(03)00340-1.

[27] F. Zucchi, A. Frignani, V. Grassi, G. Trabanelli, M. Dal Colle, The formation of a protective layer of 3-mercapto-propyl-trimethoxy-silane on copper, Corros. Sci. 49 (2007) 1570-1583. doi:10.1016/j.corsci.2006.08.019.

[28] F. Sinapi, S. Julien, D. Auguste, L. Hevesi, J. Delhalle, Z. Mekhalif, Monolayers and mixed-layers on copper towards corrosion protection, Electrochim. Acta. 53 (2008) 4228-4238. doi:10.1016/j.electacta.2007.12.061.

[29] Y.S. Li, W. Lu, Y. Wang, T. Tran, Studies of (3-mercaptopropyl)trimethoxylsilane and bis(trimethoxysilyl)ethane sol-gel coating on copper and aluminum, Spectrochim. Acta - Part A Mol. Biomol. Spectrosc. 73 (2009) 922-928. doi:10.1016/j.saa.2009.04.016.

[30] A. Balbo, A. Frignani, C. Monticelli, Influence of nanoparticles on the inhibiting efficiency of organosilane coatings on bronze. Part 1: Electrochemical characterization, in: Eurocorr 2012 (EFC Event n.330), EFC, London, UK (CD-ROM), Istanbul, Turkey, 2012: pp. 1-8 (Paper 1524).

[31] A. Balbo, C. Chiavari, C. Martini, C. Monticelli, Effectiveness of corrosion inhibitor films for the conservation of bronzes and gilded bronzes, Corros. Sci. 59 (2012) 204-212. doi:10.1016/j.corsci.2012.03.003.

[32] C. Chiavari, a. Balbo, E. Bernardi, C. Martini, F. Zanotto, I. Vassura, M.C. Bignozzi, C.Monticelli, Organosilane coatings applied on bronze: Influence of UV radiation and thermal cycles on the protectiveness, Prog. Org. Coatings. 82 (2015) 91-100. doi:10.1016/j.porgcoat.2015.01.017. 
[33] C. Chiavari, a. Balbo, E. Bernardi, C. Martini, M.C. Bignozzi, M. Abbottoni, C.Monticelli, Protective silane treatment for patinated bronze exposed to simulated natural environments, Mater. Chem. Phys. 141 (2013) 502-511. doi:10.1016/j.matchemphys.2013.05.050.

[34] S. Peng, Z. Zeng, W. Zhao, J. Chen, J. Han, X. Wu, Performance evaluation of mercapto functional hybrid silica sol - gel coating on copper surface, Surf. Coat. Technol. 251 (2014) 135-142. doi:10.1016/j.surfcoat.2014.04.017.

[35] W.J. van Ooij, D. Zhu, M. Stacy, a. Seth, T. Mugada, J. Gandhi, et al., Corrosion Protection Properties of Organofunctional Silanes-An Overview, Tsinghua Sci. Technol. 10 (2005) 639-664. doi:10.1016/S1007-0214(05)70134-6.

[36] A. Ulman, Formation and Structure of Self-Assembled Monolayers, Chem. Rev. 96 (1996) 15331554.

[37] Y.F. Xing, S.F.Y. Li, a. K.H. Lau, S.J. O'Shea, Electrochemical impedance spectroscopy study of mixed thiol monolayers on gold, J. Electroanal. Chem. 583 (2005) 124-132.

doi:10.1016/j.jelechem.2005.05.010.

[38] Y. Chen, C. Yang, F. Bin Wang, Electrochemical assessment of electrochemical oxidation stability of self-assembled monolayers on gold and preparation of binary self-assembled monolayers on gold, Electrochim. Acta. 55 (2010) 3951-3956. doi:10.1016/j.electacta.2010.02.047.

[39] M.M. Antonijevic, M.B. Petrovic, Copper Corrosion Inhibitors . A review, Int. J. Electrochem. Sci. 3 (2008) 1-28. doi:10.1016/j.ijengsci.2004.12.001.

[40] C. Chiavari, E. Bernardi, C. Martini, F. Passarini, F. Ospitali, L. Robbiola, The atmospheric corrosion of quaternary bronzes: The action of stagnant rain water, Corros. Sci. 52 (2010) 3002-3010. doi:10.1016/j.corsci.2010.05.013.

[41] E. Bernardi, C. Chiavari, B. Lenza, C. Martini, L. Morselli, F. Ospitali, et al., The atmospheric corrosion of quaternary bronzes: The leaching action of acid rain, Corros. Sci. 51 (2009) 159-170. doi:10.1016/j.corsci.2008.10.008.

[42] B. Cellini, I trattati dell'oreficeria e della scultura, secondo il codice Marciano, Hoepli, Milano, 1927.

[43] E. Bernardi, C. Chiavari, C. Martini, L. Morselli, The atmospheric corrosion of quaternary bronzes: An evaluation of the dissolution rate of the alloying elements, Appl. Phys. A. 92 (2008) 83-89. doi:10.1007/s00339-008-4451-0.

[44] M. Pourbaix, Atlas of Electrochemical Equilibria in Aqueous Solutions, Pergammon, New York, 1966.

[45] A.M. Alfantazi, T.M. Ahmed, D. Tromans, Corrosion behavior of copper alloys in chloride media, Mater. Des. 30 (2009) 2425-2430. doi:10.1016/j.matdes.2008.10.015.

[46] L.A. Giannuzzi, J.R. Michael, Ion Channeling vs. Electron Channeling Image Contrast, Microsc. Microanal. 18 (2012) 694-695. doi:10.1017/S1431927612005326.

[47] A. Robin, G.A.S. Martinez, P.A. Suzuki, Effect of cold-working process on corrosion behavior of copper, Mater. Des. 34 (2012) 319-324. doi:10.1016/j.matdes.2011.08.018. 
[48] M.D. Ynsa, J. Chamón, P.C. Gutiérrez, I. Gomez-Morilla, O. Enguita, A. I. Pardo, et al., Study of ancient Islamic gilded pieces combining PIXE-RBS on external microprobe with sem images, Appl. Phys. A. 92 (2008) 235-241. doi:10.1007/s00339-008-4497-z.

[49] P. Madakson, J.C. Liu, The interdiffusion of $\mathrm{Cu}, \mathrm{Co}$ and $\mathrm{Au}$ Thin Films at elevated temperatures., 167, 321 doi:10.1557/PROC-167-321., MRS Proc. 167 (1989) 321.

[50] E. Bernardi, D.J. Bowden, P. Brimblecombe, H. Kenneally, L. Morselli, The effect of uric acid on outdoor copper and bronze., Sci. Total Environ. 407 (2009) 2383-9. doi:10.1016/j.scitotenv.2008.12.014.

[51] S. Goidanich, L. Toniolo, S. Jafarzadeh, I.O. Wallinder, Effects of wax-based anti-graffiti on copper patina composition and dissolution during four years of outdoor urban exposure, J. Cult. Herit. 11 (2010) 288-296. doi:10.1016/j.culher.2010.02.001.

[52] G. Giuntoli, L. Rosi, M. Frediani, B. Sacchi, B. Salvadori, S. Porcinai, et al., Novel coatings from renewable resources for the protection of bronzes, Prog. Org. Coatings. 77 (2014) 892-903. doi:10.1016/j.porgcoat.2014.01.021.

[53] L. Robbiola, K. Rahmouni, C. Chiavari, C. Martini, D. Prandstraller, A. Texier, et al., New insight into the nature and properties of pale green surfaces of outdoor bronze monuments, Appl. Phys. A. 92 (2008) 161-169. doi:10.1007/s00339-008-4468-4.

[54] C. Chiavari, K. Rahmouni, H. Takenouti, S. Joiret, P. Vermaut, L. Robbiola, Composition and electrochemical properties of natural patinas of outdoor bronze monuments, Electrochim. Acta. 52 (2007) 7760-7769. doi:10.1016/j.electacta.2006.12.053.

[55] I. Mabille, a. Bertrand, E.M.M. Sutter, C. Fiaud, Mechanism of dissolution of a $\mathrm{Cu}-13 \mathrm{Sn}$ alloy in low aggressive conditions, Corros. Sci. 45 (2003) 855-866. doi:10.1016/S0010-938X(02)00207-X.

[56] L. Robbiola, J.M. Blengino, C. Fiaud, Morphology and mechanisms of formation of natural patinas on archaeological Cu-Sn alloys, Corros. Sci. 40 (1998) 2083-2111. doi:10.1016/S0010938X(98)00096-1.

[57] D.A. Scott, Periodic corrosion phenomena in bronze antiquities, Stud. Conserv. 30 (1985) 49-57.

[58] G.M. Ingo, T. De Caro, C. Riccucci, S. Khosroff, Uncommon corrosion phenomena of archaeological bronze alloys, Appl. Phys. A Mater. Sci. Process. 83 (2006) 581-588. doi:10.1007/s00339-006-3534$\mathrm{z}$.

[59] C. Soffritti, E. Fabbri, M. Merlin, G.L. Garagnani, C. Monticelli, On the degradation factors of an archaeological bronze bowl belonging to a private collection, Appl. Surf. Sci. 313 (2014) 762-770. doi:10.1016/j.apsusc.2014.06.067.

[60] I. Constantinides, A. Adriaens, F. Adams, Surface characterization of artifcial corrosion layers on copper alloy reference materials, Appl. Surf. Sci. 189 (2002) 90-101.

[61] O. Oudbashi, S. Emami, H. Ahmadi, P. Davami, Micro-stratigraphical investigation on corrosion layers in ancient Bronze artefacts by scanning electron microscopy energy dispersive spectrometry and optical microscopy, Herit. Sci. 1 (2013) 1-21. doi:10.1186/2050-7445-1-21. 
[62] J.H. Payer, G. Ball, B.I. Rickett, H.S. Kim, Role of transport properties in corrosion product growth, Mater. Sci. Eng. A. 198 (1995) 91-102. doi:10.1016/0921-5093(95)80063-Z.

[63] M.P. Casaletto, G.M. Ingo, M. Albini, a. Lapenna, I. Pierigè, C. Riccucci, et al., An integrated analytical characterization of corrosion products on ornamental objects from the necropolis of Colle Badetta-Tortoreto (Teramo, Italy), Appl. Phys. A Mater. Sci. Process. 100 (2010) 801-808. doi:10.1007/s00339-010-5675-3. 


\section{FIGURE CAPTIONS}

Figure 1: $R_{p}$ estimation from Nyquist plots recorded on bronze under short exposure times in Wet\&Dry conditions (TOW of $36 \mathrm{~h}$ corresponding to $1.5 \mathrm{~d}$, , under higher magnification in the insert) and on gilded bronze (TOW of $240 \mathrm{~h}$ corresponding to $10 \mathrm{~d}$ ).

Figure 2: General view of the surface (a) and FIB cross-section (b,c) images (SE-SEM) of as-supplied firegilded bronze samples, showing the morphology of the gilded layer in smooth (b) and porous areas (c).

Figure 3: FIB cross-section image of fire-gilded bronze, where ion channelling contrast highlights the microstructure of both the gold layer (Au, with annealing twins) and the outermost layer of the substrate (SHB, strain-hardened bronze grains, due to mechanical polishing before gilding).

Figure 4: $\mathrm{R}_{\mathrm{p}}$ and $\mathrm{E}_{\mathrm{cor}}$ values collected by EIS on both gilded bronze and bare bronze (investigated as reference material), during wet\&dry tests in concentrated acid rain up to 10 days ( $240 \mathrm{~h}$ ) of TOW.

Figure 5: Polarization curves recorded on bronze (a) and gilded bronze or gold foil (b) during wet\&dry tests (W\&D) at increasing TOW in concentrated acid rain.

Figure 6: Cross-section images (SE-SEM) of fire-gilded bronze samples after accelerated ageing by wet\&dry (a) and dropping (b) tests (TOW=240 $\mathrm{h}$ corresponding to $10 \mathrm{~d}$ ). Localised corrosion damages in the form of craters are visible at the gold/bronze interface, even though to a lesser extent in the case of wet\&dry.

Figure 7: SEM-BSE image (a) and EDS X-Ray maps (b-e) showing elemental distribution in the cross section of a corrosion crater at the gold/bronze interface in an uncoated fire-gilded sample after exposure to long-term dropping tests ( $\mathrm{TOW}=720 \mathrm{~h}$ corresponding to $30 \mathrm{~d}$ ).

Figure 8: Raman spectra of the central area of the corrosion crater in Fig. 6. Cuprite detected as the main corrosion product (peak labels in bold). Minor contributions due to the mounting resin (peak labels in italics), which is also responsible for fluorescence.

Figure 9: FIB cross sections of a corrosion crater at the gold/bronze interface in an uncoated fire-gilded sample after exposure to long-term dropping tests (TOW=720 h corresponding to $30 \mathrm{~d}$ ). FEG-SEM images $(a, c)$ and corresponding EDS spectra (b, d).

Figure 10: Mass decrease $\left(\mathrm{mg} \mathrm{cm}^{-2}\right)(\mathrm{a})$, cumulative $\mathrm{Cu}$ release $\left(\mu \mathrm{g} \mathrm{cm}^{-2}\right)(\mathrm{b})$ and cumulative $\mathrm{Pb}$ release $(\mu \mathrm{g}$ $\mathrm{cm}^{-2}$ ) (c) as a function of Time Of Wetness (TOW) for gilded bronze and PropS-SH coated gilded bronze exposed to dropping tests.

Figure 11: FEG-SEM images of the free surface of fire-gilded bronze before (a) and after (b) the deposition of a PropS-SH coating. BSE-SEM cross section images of fire-gilded bronze after long-term dropping test (TOW=720 h corresponding to $30 \mathrm{~d}$ ): uncoated (c) and PropS-SH coated (d) samples.

Figure 12: FIB-FEG/SEM images of the cross section in a PropS-SH coated, fire-gilded sample after longterm dropping test (TOW=720 $\mathrm{h}$ corresponding to $30 \mathrm{~d}$ ): a small corrosion crater was observed at the gold/bronze interface in (b). 


\section{FIGURES}

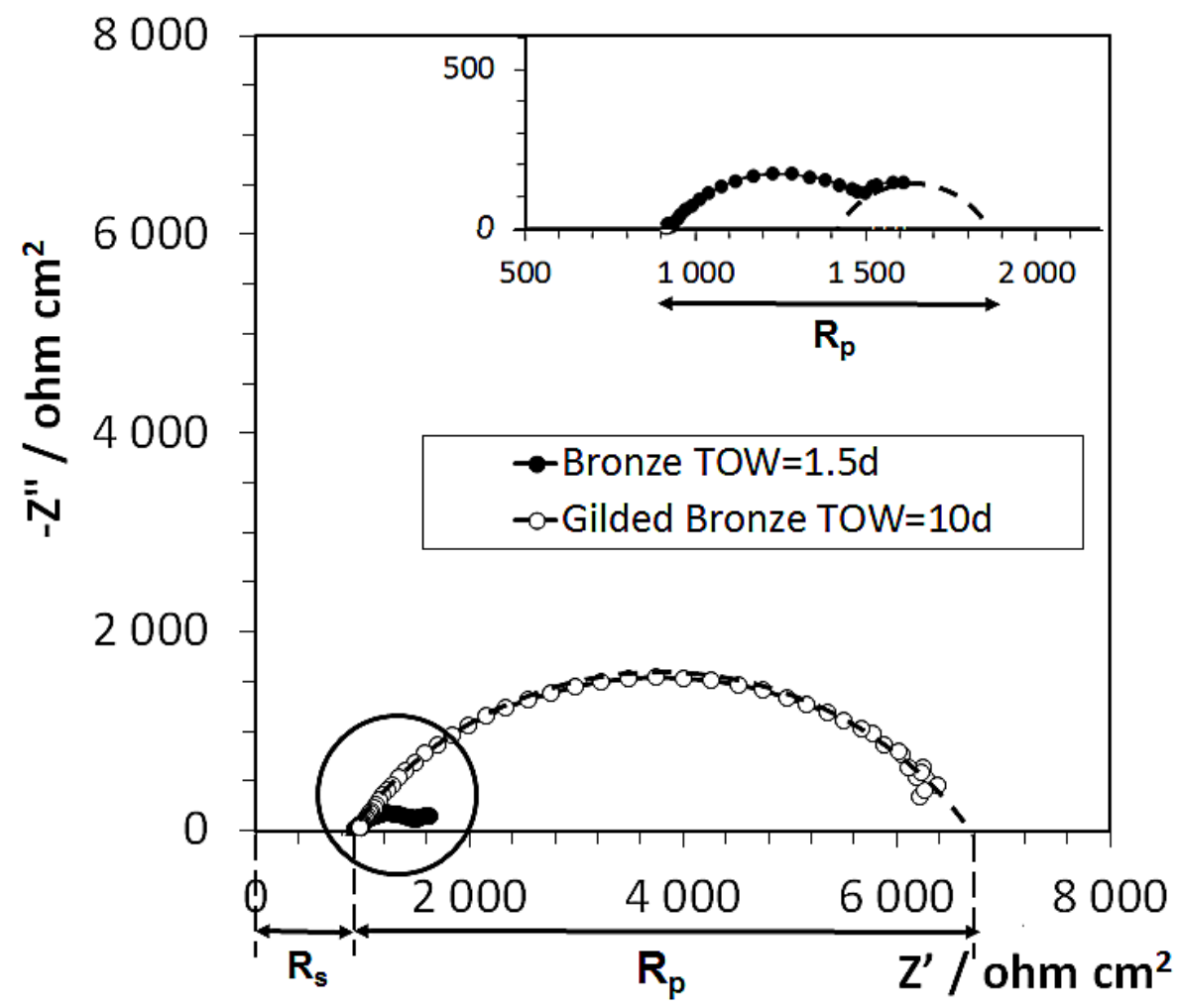

Figure 1: $R_{p}$ estimation from Nyquist plots recorded on bronze under short exposure times in Wet\&Dry conditions (TOW of $36 \mathrm{~h}$ corresponding to $1.5 \mathrm{~d}$, , under higher magnification in the insert) and on gilded bronze (TOW of $240 \mathrm{~h}$ corresponding to $10 \mathrm{~d}$ ). 


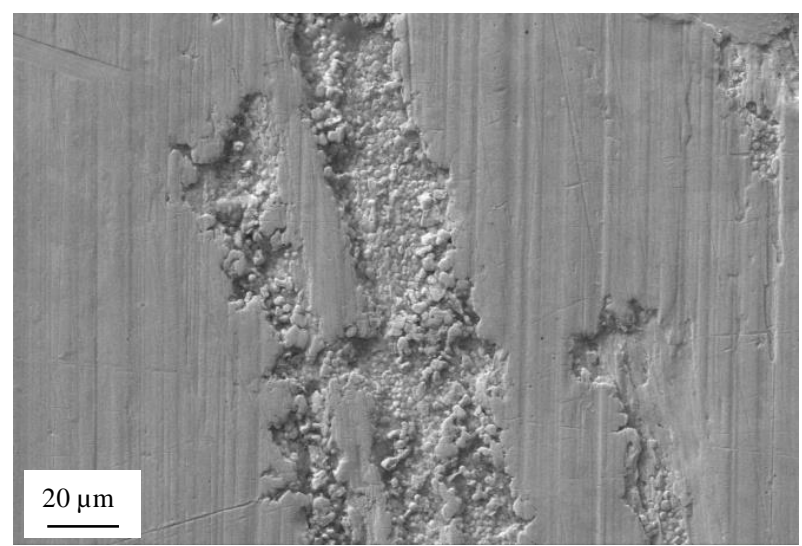

(a)

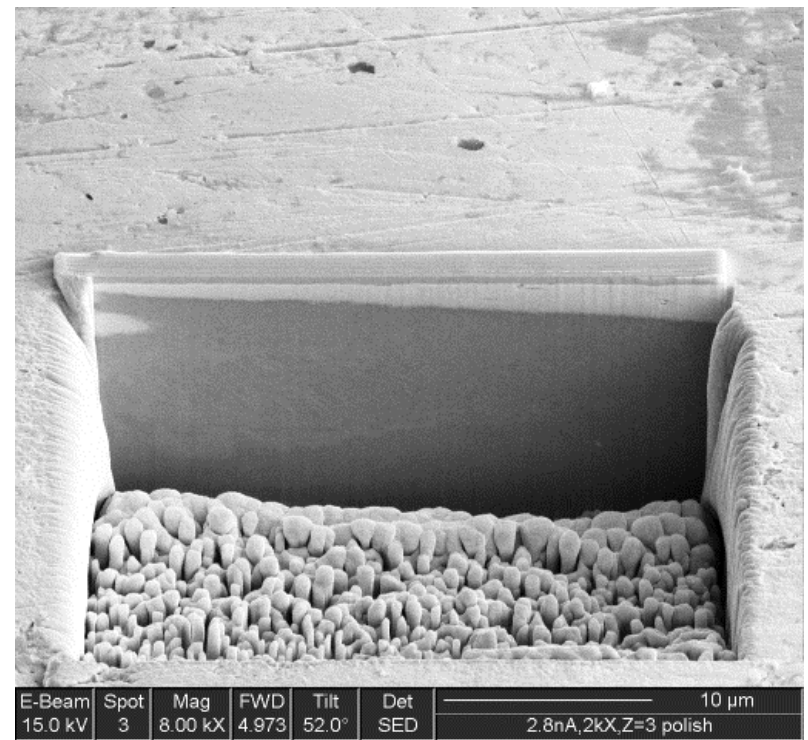

(b)

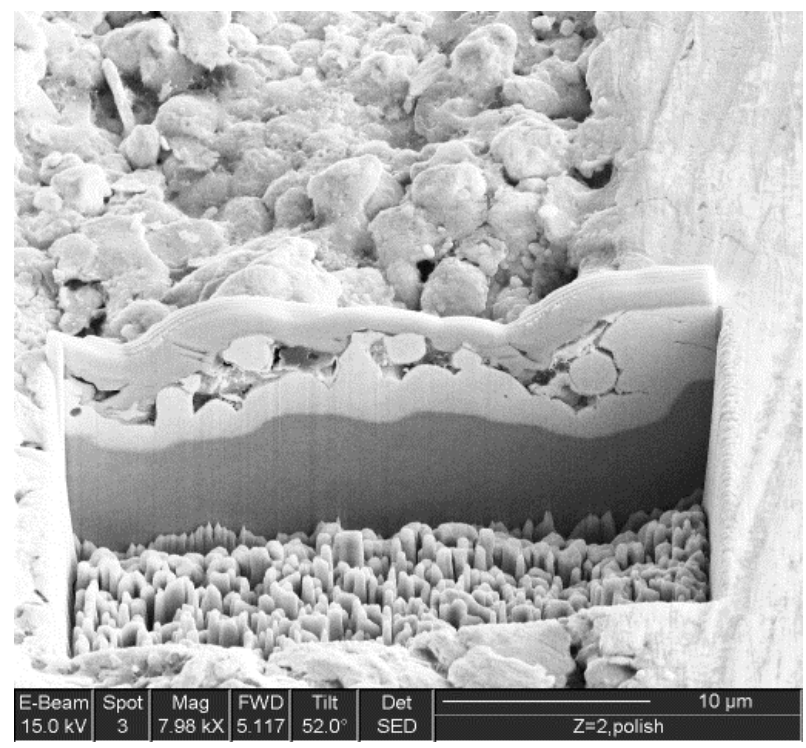

(c)

Figure 2: General view of the surface (a) and FIB cross-section (b,c) images (SE-SEM) of as-supplied firegilded bronze samples, showing the morphology of the gilded layer in smooth (b) and porous areas (c). 


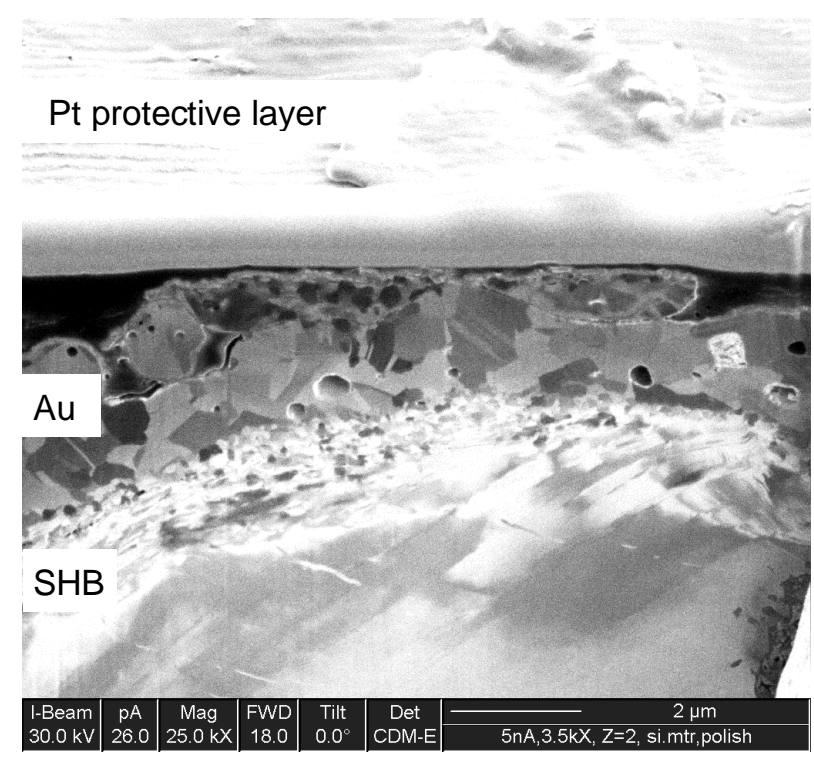

Figure 3: FIB cross-section image of fire-gilded bronze, where ion channelling contrast highlights the microstructure of both the gold layer ( $\mathrm{Au}$, with annealing twins) and the outermost layer of the substrate (SHB, strain-hardened bronze grains, due to mechanical polishing before gilding). 


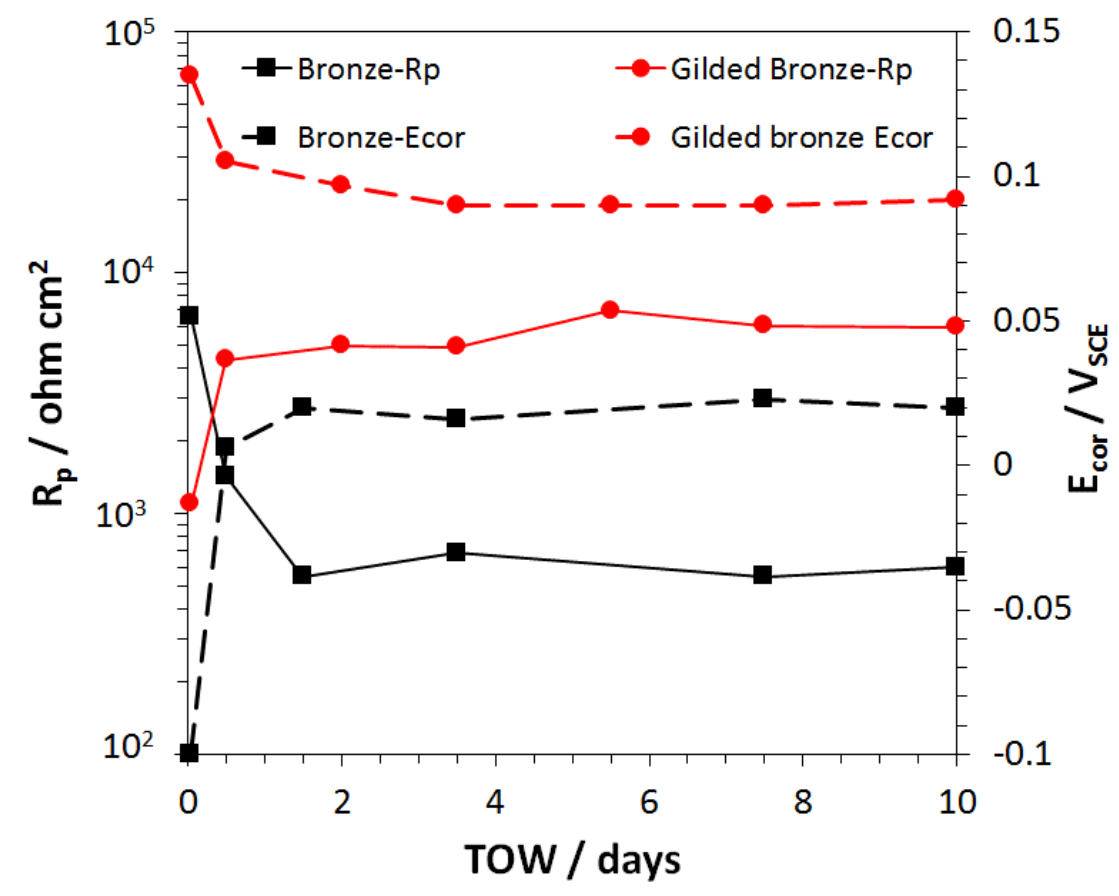

Figure 4: $\mathrm{R}_{\mathrm{p}}$ and $\mathrm{E}_{\mathrm{cor}}$ values collected by EIS on both gilded bronze and bare bronze (investigated as reference material), during wet\&dry tests in concentrated acid rain up to 10 days $(240 \mathrm{~h})$ of TOW. 


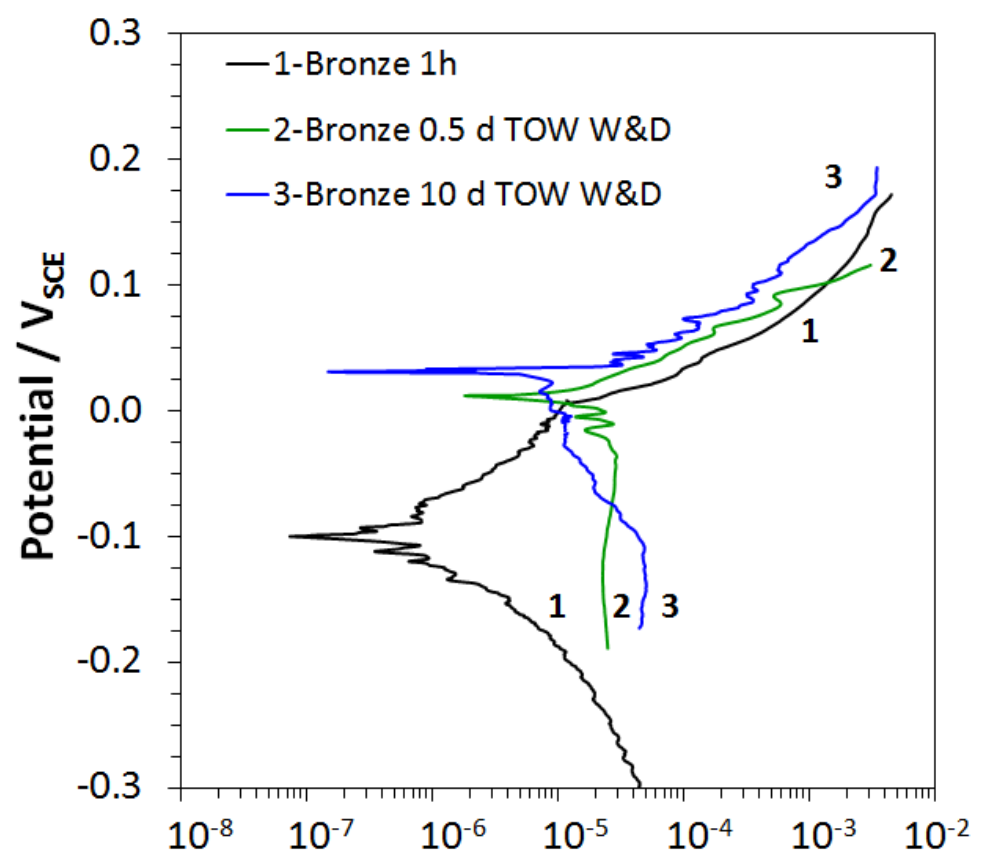

\section{Current density / $\mathrm{A} \mathrm{cm}^{-2}$}

(a)

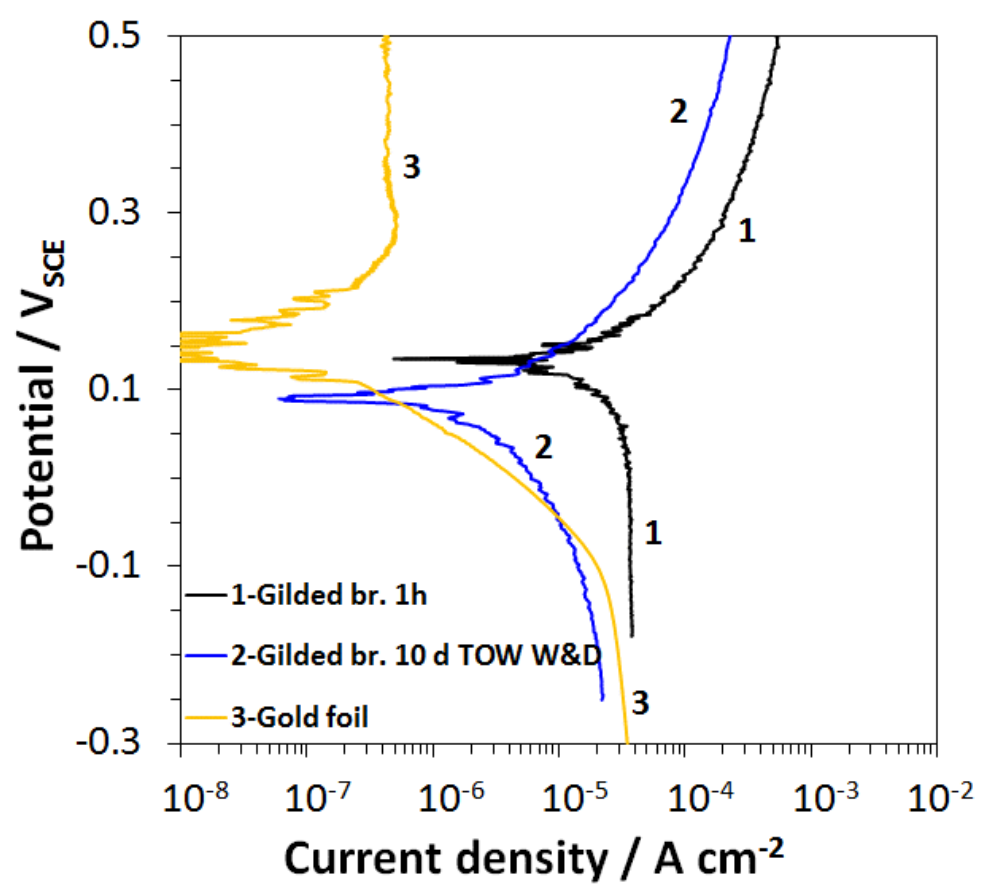

(b)

Figure 5: Polarization curves recorded on bronze (a) and gilded bronze or gold foil (b) during wet\&dry tests (W\&D) at increasing TOW in concentrated acid rain. 


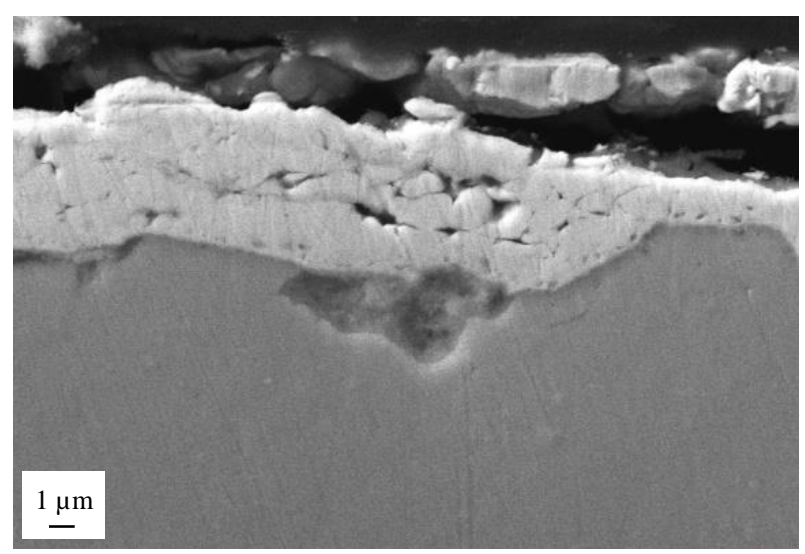

(a)

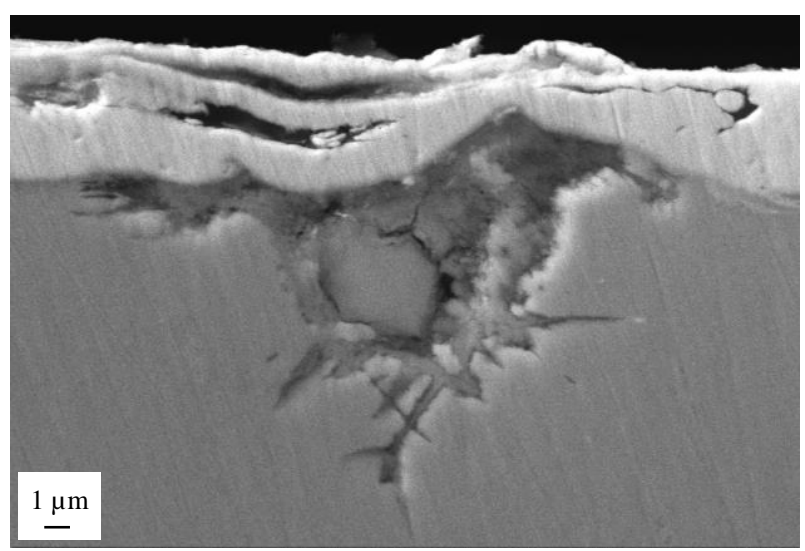

(b)

Figure 6: Cross-section images (SE-SEM) of fire-gilded bronze samples after accelerated ageing by wet\&dry (a) and dropping (b) tests (TOW=240 h corresponding to $10 \mathrm{~d}$ ). Localised corrosion damages in the form of craters are visible at the gold/bronze interface, even though to a lesser extent in the case of wet\&dry. 


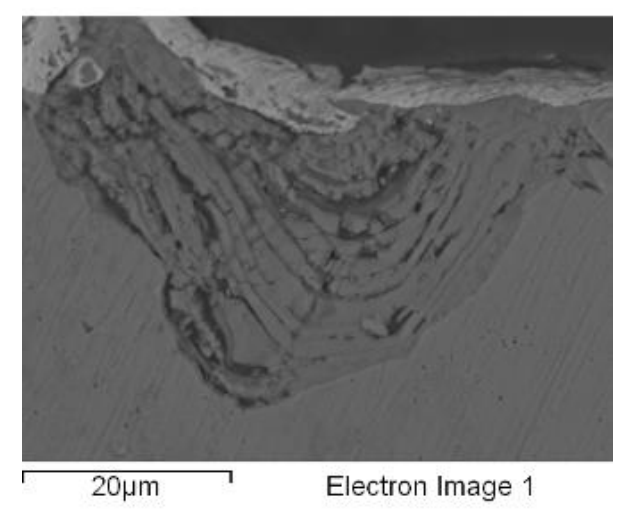

(a)

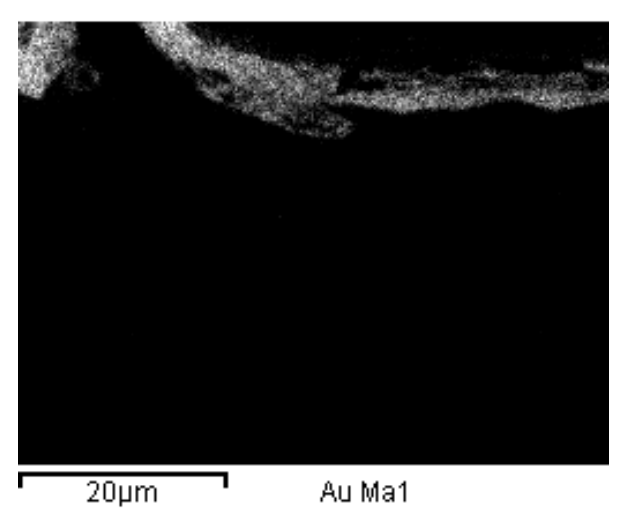

(b)

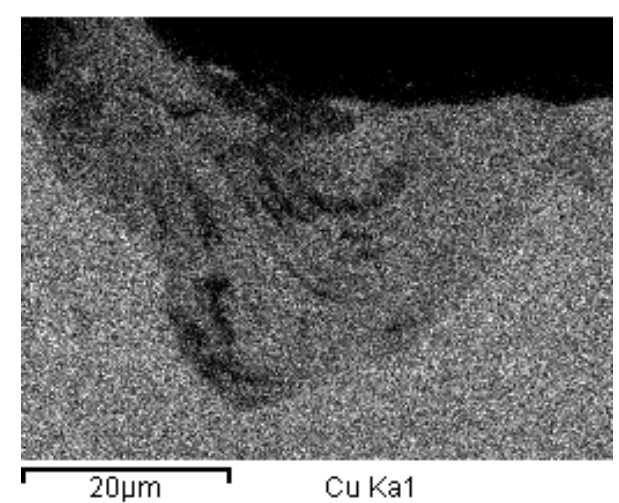

(d)

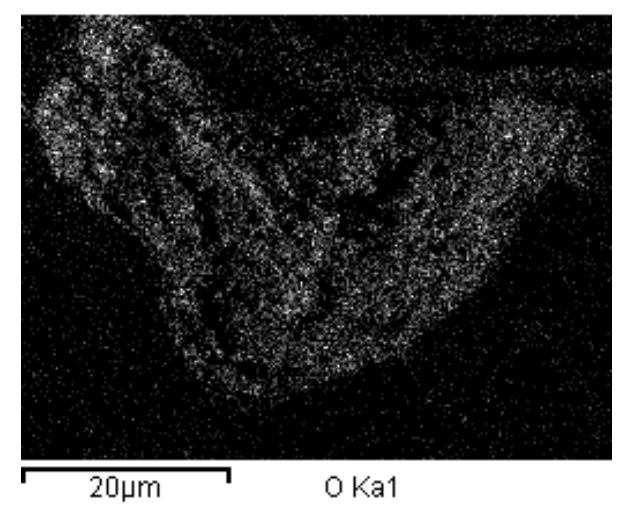

(c)

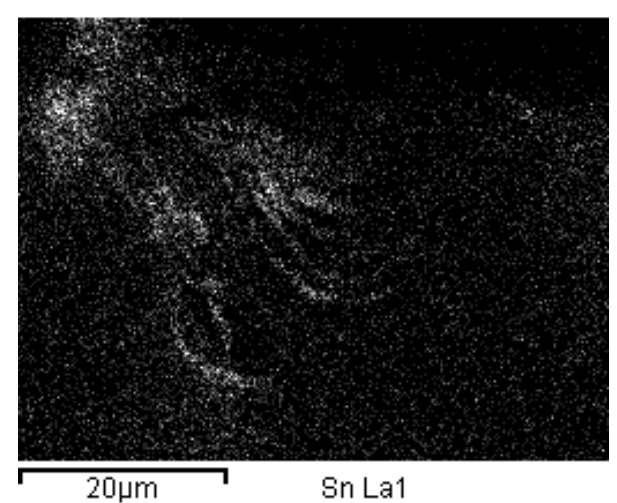

(e)

Figure 7: SEM-BSE image (a) and EDS X-Ray maps (b-e) showing elemental distribution in the cross section of a corrosion crater at the gold/bronze interface in an uncoated fire-gilded sample after exposure to long-term dropping tests ( $\mathrm{TOW}=720 \mathrm{~h}$ corresponding to $30 \mathrm{~d}$ ). 


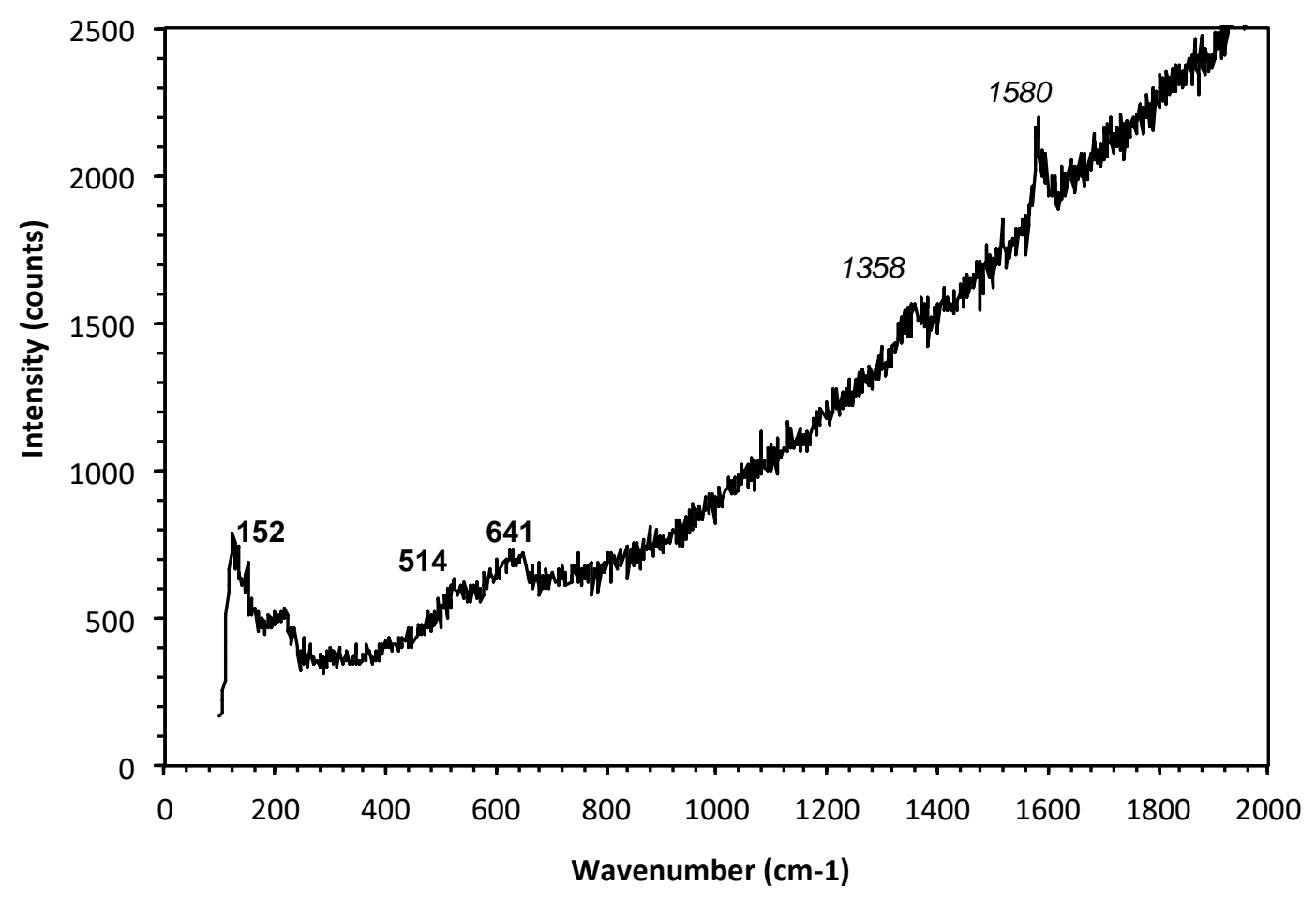

Figure 8: Raman spectra of the central area of the corrosion crater in Fig. 6. Cuprite detected as the main corrosion product (peak labels in bold). Minor contributions due to the mounting resin (peak labels in italics), which is also responsible for fluorescence. 


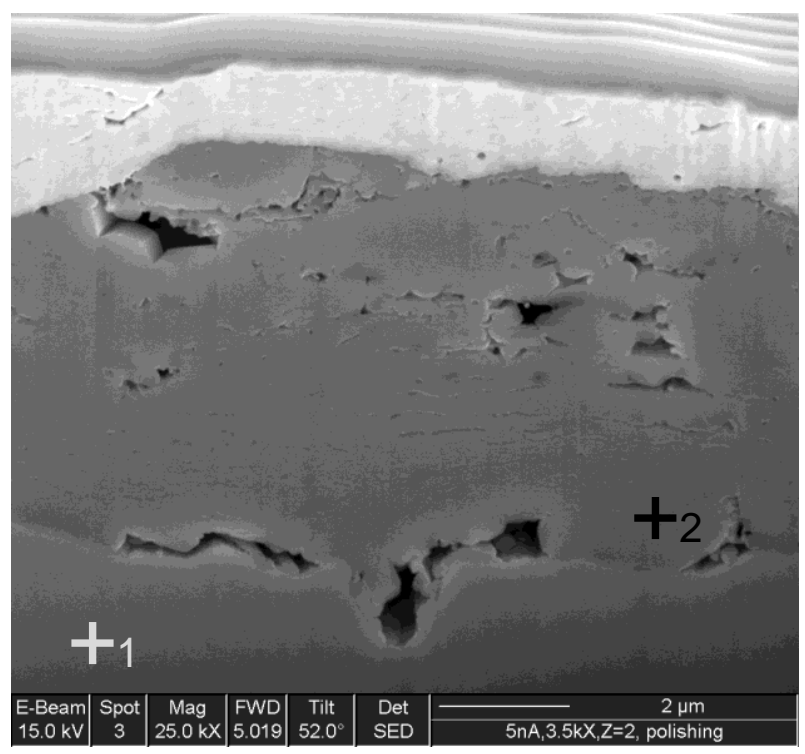

(a)

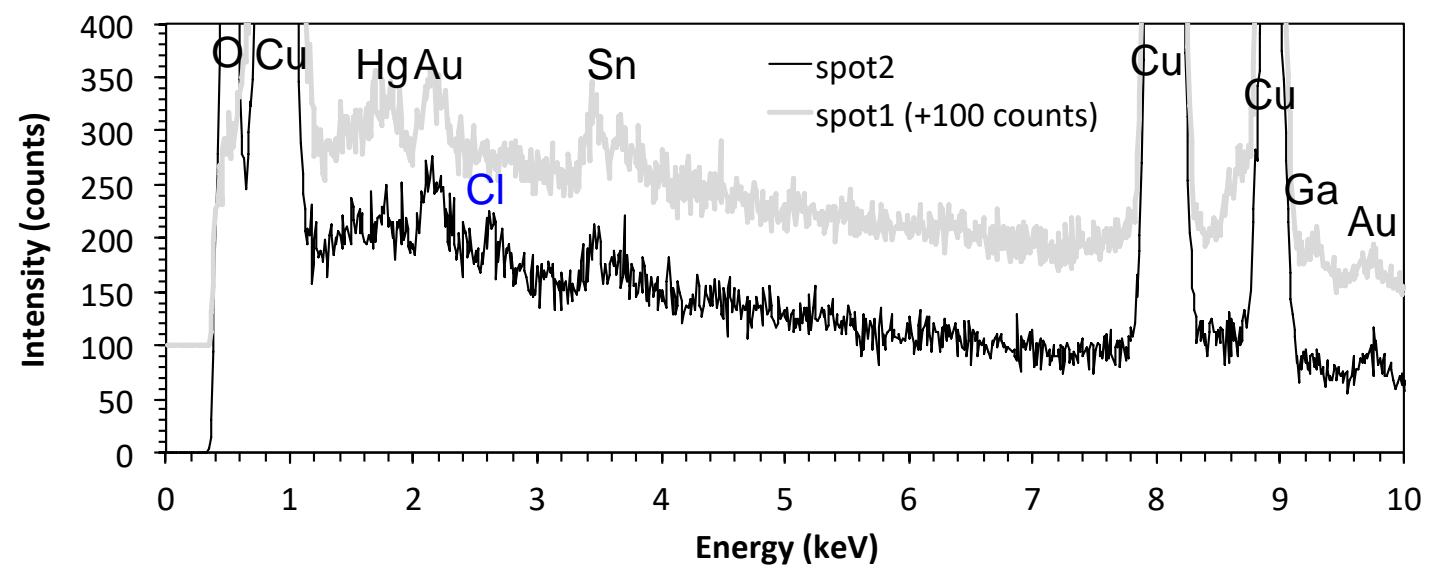

(b)

Figure 9 (continues in next page) 


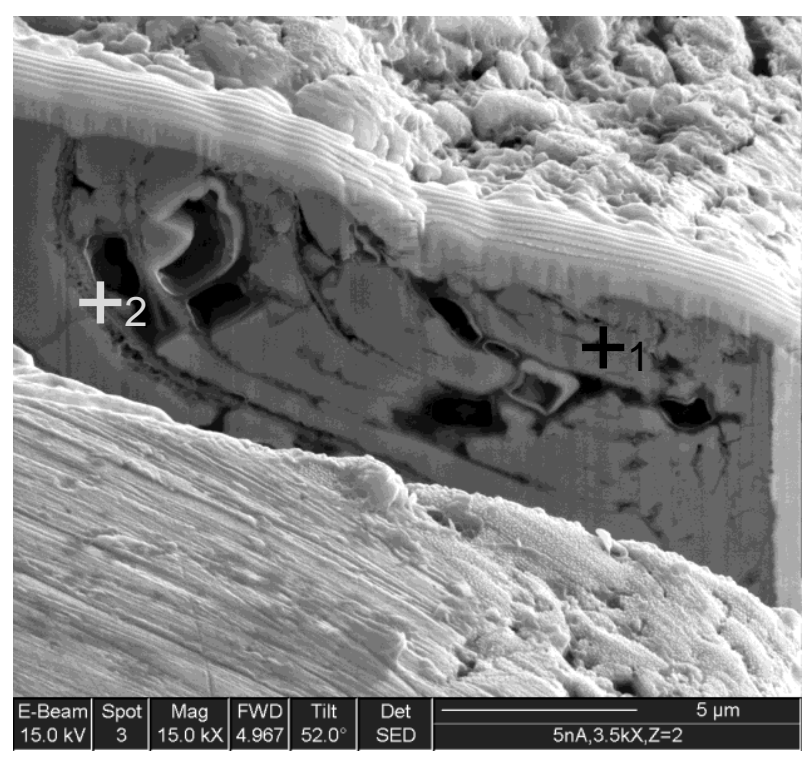

(c)

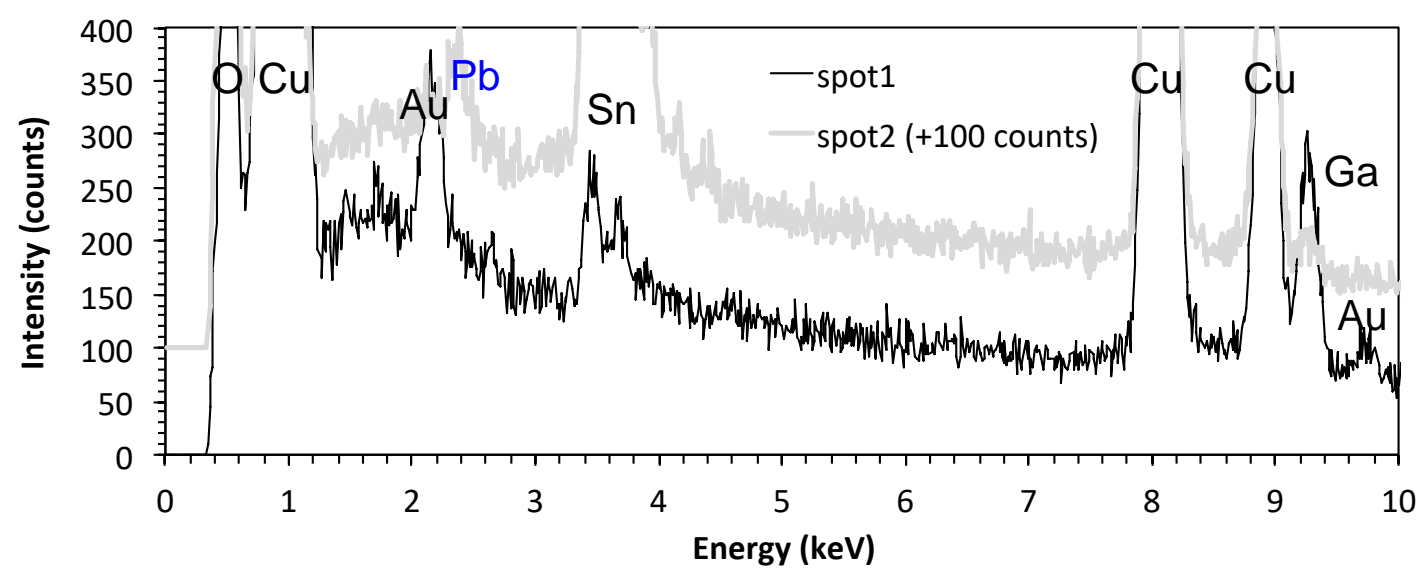

(d)

Figure 9: FIB cross sections of a corrosion crater at the gold/bronze interface in an uncoated firegilded sample after exposure to long-term dropping tests (TOW=720 h corresponding to $30 \mathrm{~d}$ ). FEG-SEM images $(a, c)$ and corresponding EDS spectra $(b, d)$. 


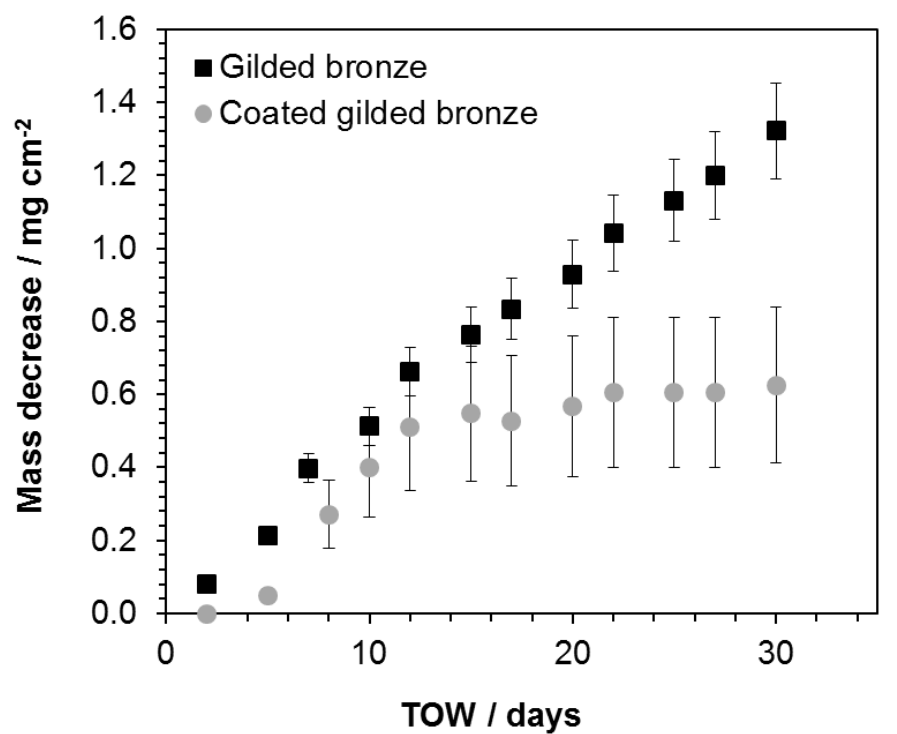

(a)

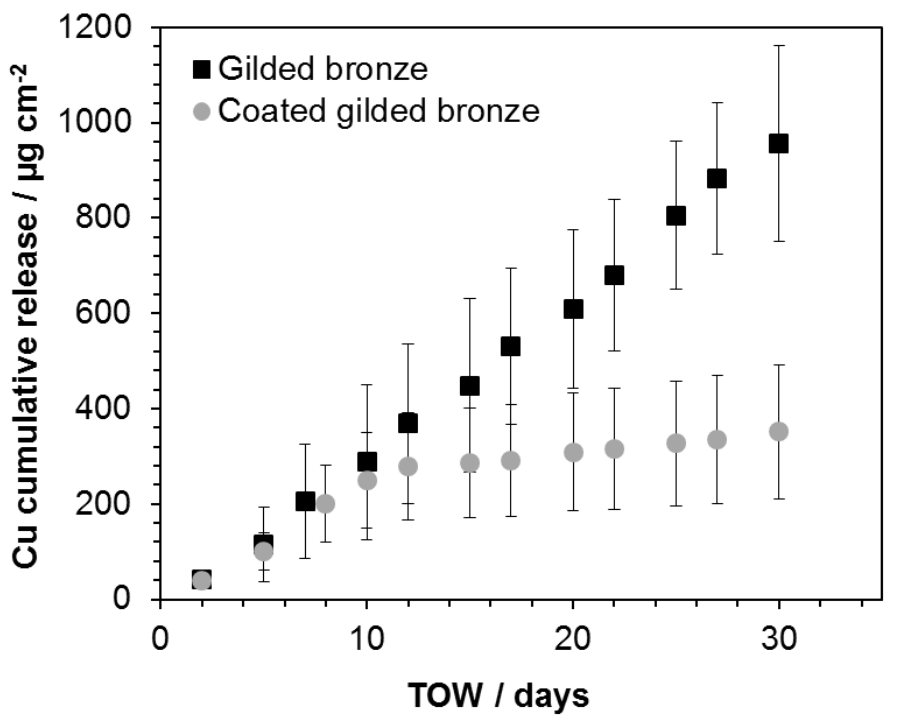

(b)

Figure 10 (continues in next page) 


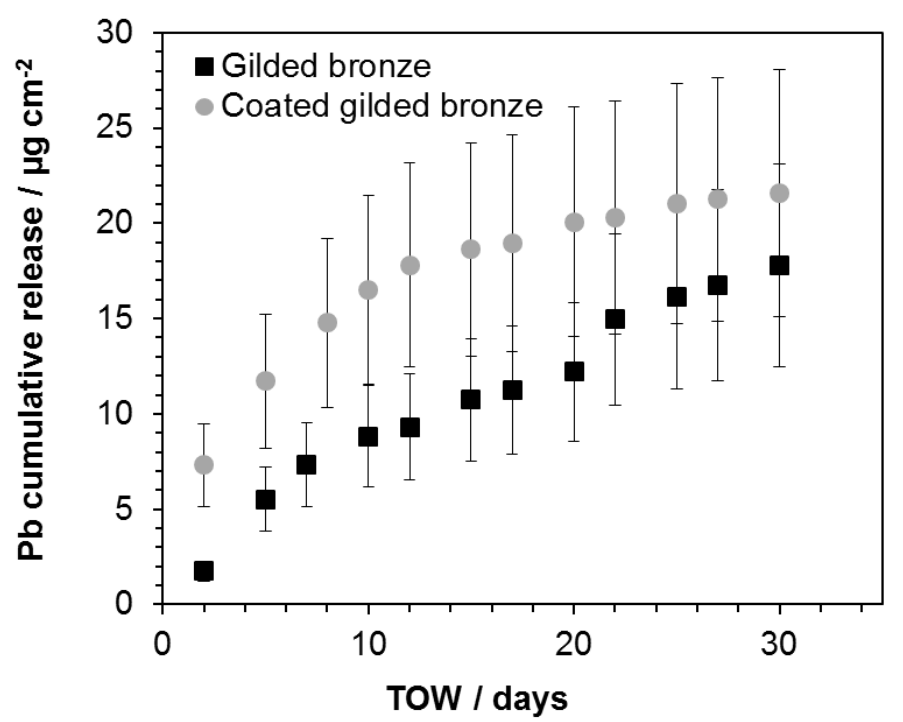

(c)

Figure 10: Mass decrease $\left(\mathrm{mg} \mathrm{cm}^{-2}\right)$ (a), cumulative $\mathrm{Cu}$ release $\left(\mu \mathrm{g} \mathrm{cm}^{-2}\right)(\mathrm{b})$ and cumulative $\mathrm{Pb}$ release $\left(\mu \mathrm{g} \mathrm{cm}^{-2}\right)$ (c) as a function of Time Of Wetness (TOW) for gilded bronze and PropS-SH coated gilded bronze exposed to dropping tests. 


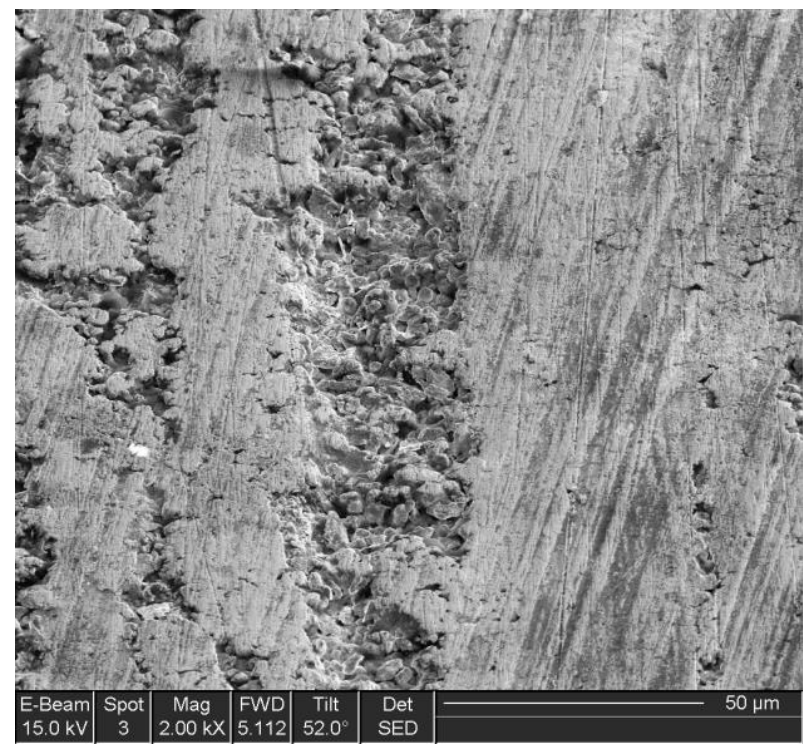

(a)

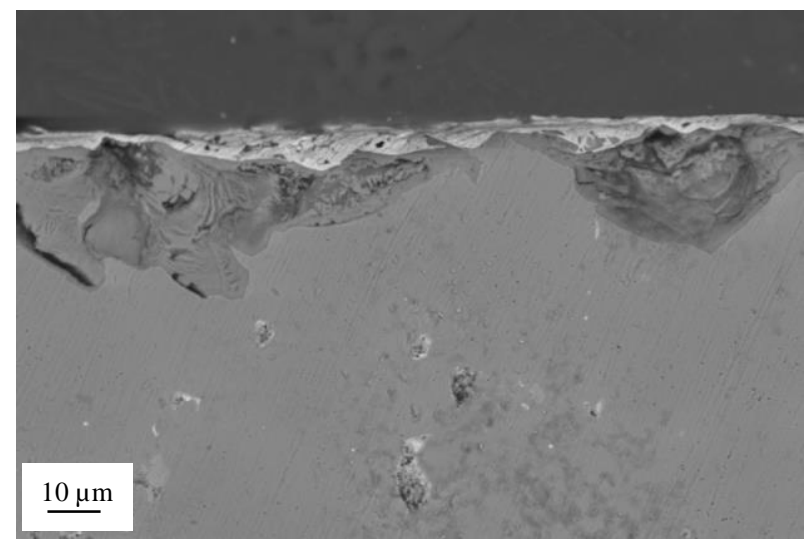

(c)

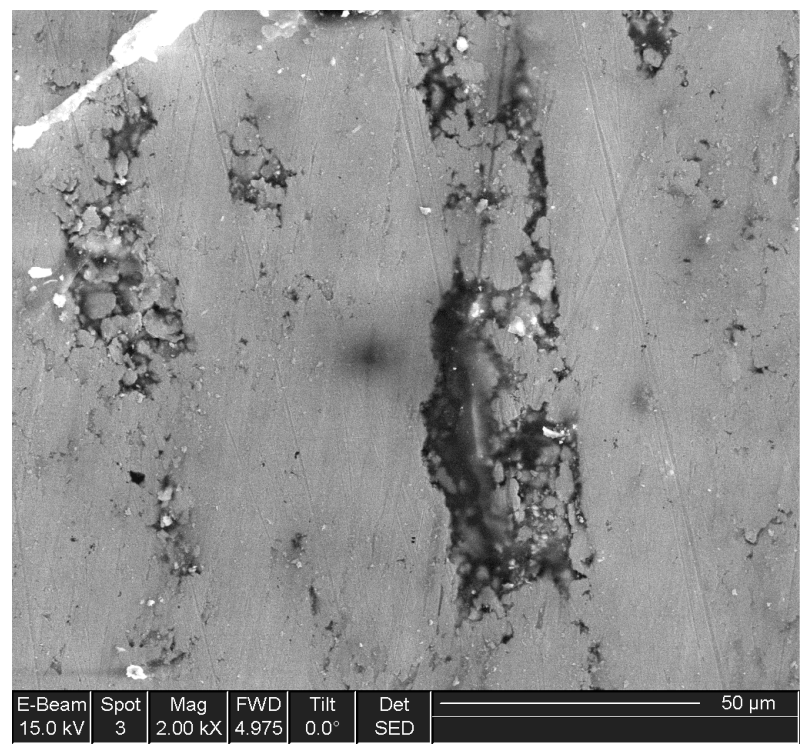

(b)

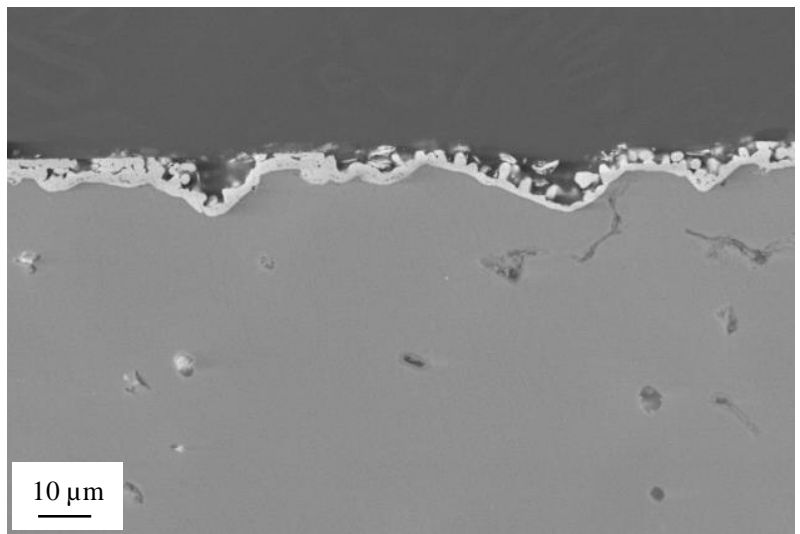

(d)

Figure 11: FEG-SEM images of the free surface of fire-gilded bronze before (a) and after (b) the deposition of a PropS-SH coating. BSE-SEM cross section images of fire-gilded bronze after longterm dropping test (TOW=720 h corresponding to $30 \mathrm{~d}$ ): uncoated (c) and PropS-SH coated (d) samples. 


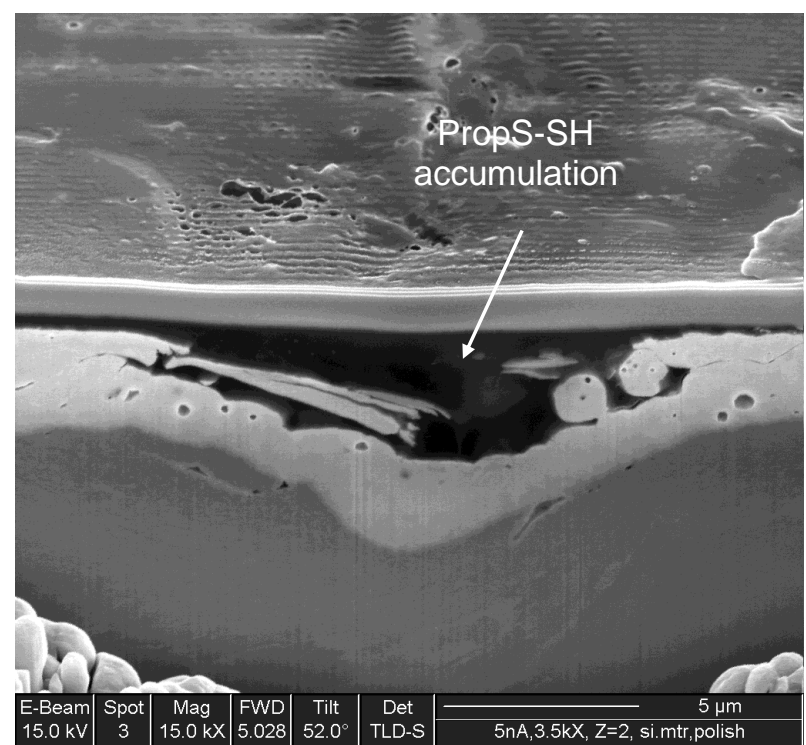

(a)

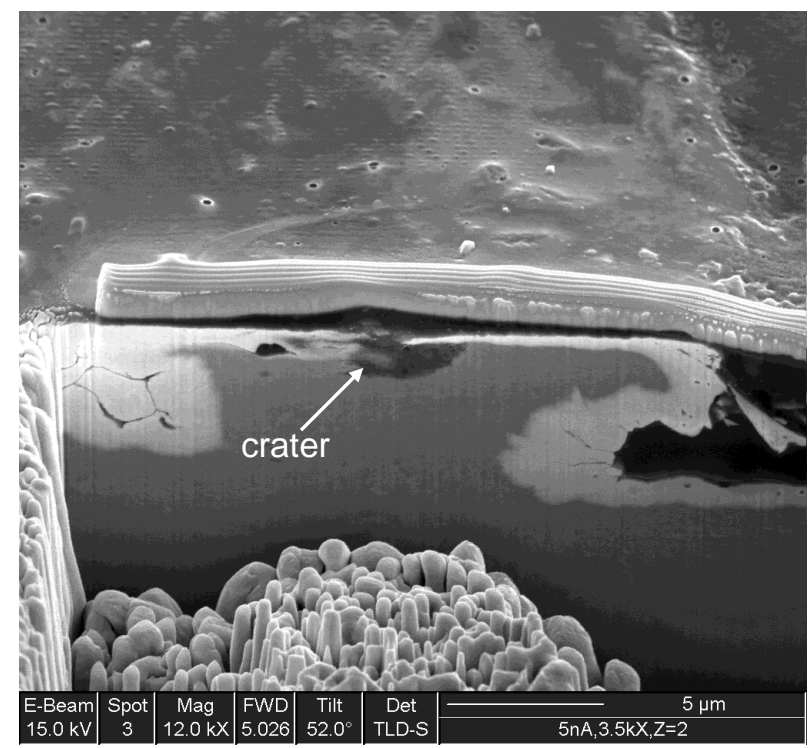

(b)

Figure 12: FIB-FEG/SEM images of the cross section in a PropS-SH coated, fire-gilded sample after long-term dropping test (TOW=720 h corresponding to $30 \mathrm{~d}$ ): a small corrosion crater was observed at the gold/bronze interface in (b). 


\section{TABLES}

Table 1: Ion concentrations, measured $\mathrm{pH}$, electrical conductivity and composition of the artificial acid rain. The tenfold concentrated acid rain adopted in the preliminary electrochemical test had a tenfold higher conductivity and a $\mathrm{pH}$ value of 3.3.

\begin{tabular}{|c|c|c|c|c|c|c|c|c|c|}
\hline \multicolumn{8}{|c|}{ Ion concentrations $\left(m g L^{-1}\right)$} & \multirow[t]{2}{*}{$p H$} & \multirow{2}{*}{$\begin{array}{l}\text { Conductivity at } \\
25^{\circ} \mathrm{C}\left(\mu \mathrm{S} \mathrm{cm}^{-1}\right)\end{array}$} \\
\hline $\mathrm{Cl}^{-}$ & $\mathrm{NO}_{3}{ }^{-}$ & $\mathrm{NH}_{4}^{+}$ & $\mathrm{SO}_{4}{ }^{2-}$ & $\mathrm{HCOO}^{-}$ & $\mathrm{CH}_{3} \mathrm{COO}^{-}$ & $\mathrm{Na}^{+}$ & $\mathrm{Ca}^{2+}$ & & \\
\hline 1.27 & 4.62 & 1.05 & 1.90 & 0.05 & 0.23 & 0.53 & 0.34 & 4.3 & 34.5 \\
\hline
\end{tabular}

Artificial acid rain composition $\left(m g L^{-1}\right)$ :

Ammonium sulfate (1.50); Ammonium chloride (1.92); Calcium sulfate dihydrate (1.44);

Sodium nitrate (1.51); Sodium acetate anhydrous (0.32); Sodium formate (0.08); Nitric acid $65 \%$ suprapur (5.50). Analytical grade salts were used.

Table 2: Cumulative metal release $\left(\mu \mathrm{g} / \mathrm{cm}^{2}\right)$ from bare bronze and gilded bronze during short-term wet\&dry and dropping tests (TOW=240 h corresponding to $10 \mathrm{~d}$ ).

\begin{tabular}{lcccc}
\hline & \multicolumn{2}{c}{ Wet\&Dry } & \multicolumn{2}{c}{ Dropping } \\
\cline { 2 - 5 } & $\mathrm{Cu}$ & $\mathrm{Pb}$ & $\mathrm{Cu}$ & $\mathrm{Pb}$ \\
\hline Bare bronze & $52 \pm 4$ & $12 \pm 2$ & $1774 \pm 266$ & $67 \pm 13$ \\
Gilded bronze & $30 \pm 12$ & $0.38 \pm 0.01$ & $288 \pm 150$ & $9 \pm 5$ \\
\hline
\end{tabular}

Table 3: Colour variations in the CIELAB colour space for: (a) gilded bronze after exposure to long-term dropping tests (TOW=720 h corresponding to $30 \mathrm{~d}$ ); (b) gilded bronze after coating by PropS-SH; (c) gilded bronze coated by PropS-SH after exposure to long-term dropping tests (TOW=720 h). $\Delta \mathrm{L}^{*}, \Delta \mathrm{a}^{*}$ and $\Delta \mathrm{b}^{*}$ represent the variations on the lightness, the red/green and the yellow/blue coordinates respectively; $\Delta \mathrm{E}^{*}$ represents the total colour variation calculated as described in section 2.3.

\begin{tabular}{ccccc}
\hline & $\Delta L^{*}$ & $\Delta a^{*}$ & $\Delta b^{*}$ & $\Delta E^{*}$ \\
\hline (a) & $-1 \pm 3$ & $-0.3 \pm 0.4$ & $-4 \pm 2$ & $5 \pm 2$ \\
(b) & $3 \pm 1$ & $-1.6 \pm 0.7$ & $0.2 \pm 0.3$ & $4 \pm 1$ \\
(c) & $2 \pm 2$ & $1.4 \pm 0.3$ & $1.9 \pm 0.8$ & $3 \pm 2$ \\
\hline
\end{tabular}

Table 4: Inhibiting efficiency of $\mathrm{Cu}\left(\eta_{C u}\right)$ and $\mathrm{Pb}\left(\eta_{P b}\right)$ release induced (a) by the gilding layer on bare bronze and (b) by PropS-SH coating on the gilded bronze after long-term dropping tests ( $\mathrm{TOW}=720 \mathrm{~h}$, corresponding to $30 \mathrm{~d}$ ).

\begin{tabular}{lcc}
\hline Coating & $\eta_{C u}$ & $\eta_{P b}$ \\
\hline (a) Gilding on bare bronze & $82 \%$ & $88 \%$ \\
\hline (b) PropS-SH on gilded bronze & $63 \%$ & n.d.* \\
\hline *not detectable & &
\end{tabular}


